\title{
A synthesis of space-time variability in multicomponent flood response
}

\author{
Yiwen Mei, Xinyi Shen, and Emmanouil N. Anagnostou \\ Civil and Environmental Engineering, University of Connecticut, Storrs, CT, USA \\ Correspondence to: Emmanouil N. Anagnostou (emmanouil.anagnostou@uconn.edu)
}

Received: 22 May 2016 - Discussion started: 15 June 2016

Revised: 20 November 2016 - Accepted: 5 March 2017 - Published: 3 May 2017

\begin{abstract}
Catchment flood response consists of multiple components of flow originating from different surface and subsurface layers. This study proposes an extension of Viglione et al. (2010a) analytical framework to represent the dependence of catchment flood response to the different runoff generation processes. The analytical framework is compared to simulations from a distributed hydrologic model. A large number of rainfall-runoff events from three catchments of Tar River basin in North Carolina are used to illustrate the analytical framework. Specifically, the framework is used to estimate three flood event characteristics (cumulative runoff volume, centroid, and "spreadness" of hydrograph) through three corresponding framework parameters: the rainfall excess and the mean and variance of catchment response time. Results show that, under the smooth topographic setups of the study area, the spatial and/or temporal correlation between rainfall and runoff generation are insignificant to flood response; delay in flood response due to runoff generation and routing are of equal importance; the shape of the flood is mainly controlled by the variability in runoff generation stage but with non-negligible contribution from the runoff routing stage. Sensitivity tests show that the framework's main error source is the systematic underestimation of the flood event's centroid and spreadness, while the random error is relatively low.
\end{abstract}

\section{Introduction}

Catchment flood response, or in a more general sense, the water balance at basin scale, is controlled by a range of hydrological processes with each of them contributing a different level of spatiotemporal variability (precipitation, surface runoff, infiltration, routing, etc.) (Skøien et al., 2003; Skøien and Blöschl, 2006; Merz and Blöschl, 2009; RodríguezBlanco et al., 2012; Palleiro et al., 2014; Zoccatelli et al., 2015). Many of these studies have investigated how these processes are linked with the catchment flood response and what the relative importance of each of these processes is in controlling the properties of the flood being generated. For example, it has been argued that only a portion of spacetime characteristics of the flood response process will emerge to control the dynamics of a flood hydrograph due to the catchment dampening effect (Skøien et al., 2003; Smith et al., 2004; Skøien and Blöschl, 2006), and this dampening effect varies dynamically according to the hydrogeological properties of the catchment and features of the triggering storm, implying a shift of relative importance of processes in catchment flood response under different flood regimes (Sivapalan, et al., 2004; Smith et al., 2002, 2005; Sangati et al., 2009; Mejía and Moglen, 2010; Volpi et al., 2012; Mei et al., 2014). The answers to these questions are intimately related to the development of a comprehensive framework that can generalize the estimation of streamflow spatiotemporal variability by a synthesis of various catchment processes under different hydrometeorological and geomorphological controls (Blöschl, 2006).

Describing catchment flood response based on a set of spatiotemporal variables in storm response (i.e., rainfall, runoff generation, and routing) has been established and utilized since the late 1990s (Woods and Sivapalan, 1999; Smith et al., 2005; Viglione et al., 2010a; Mejía and Moglen, 2010; Mei et al., 2014; Zoccatelli et al., 2011, 2015). The essence of such an analytical framework is to diagnose the relative importance of rainfall space-time processes that influence the runoff generation (i.e., cumulative flow volume, hydro- 


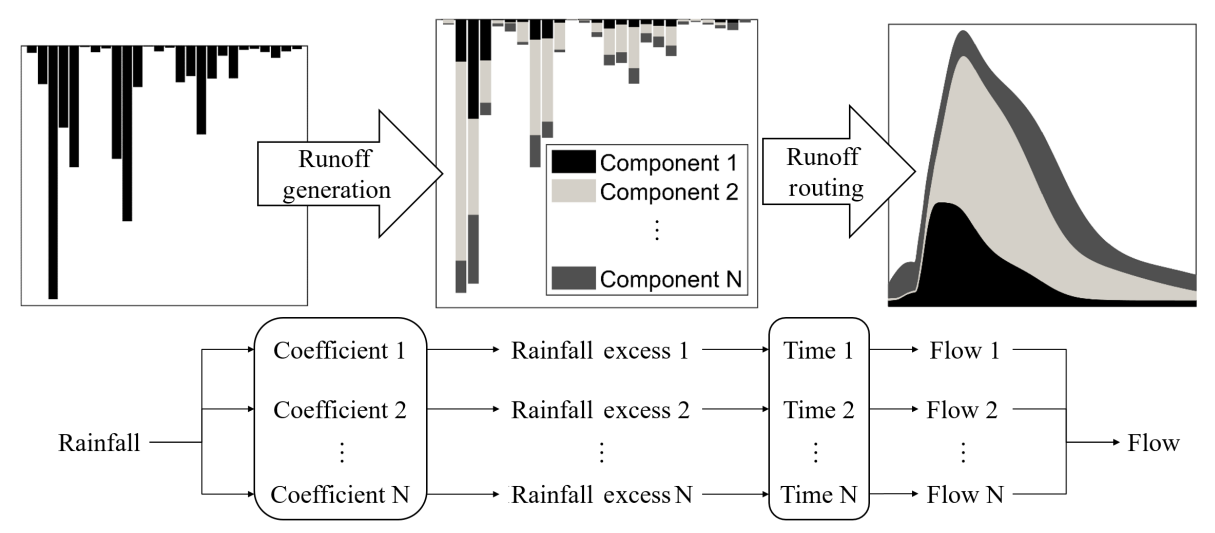

Figure 1. Schematic of the analytical framework.

graph timing, and shape). The first work that synthesized the space-time variables into a holistic analytical framework is that of Woods and Sivapala (1999). That framework used the "stationary rainfall" assumption, which can be interpreted as no movement of rainfall over the catchment. This assumption is strong, but it is considered reasonable only for shortduration or orographic-enhanced storms, which have relatively fixed spatial patterns over time. This framework assumption was applied in subsequent studies by Mejía and Moglen (2010) and Zoccatelli et al. (2010). Specifically, Zoccatelli et al. (2010) investigated the influence introduced by neglecting the spatial information of rainfall distribution in flow generation. Their study showed a larger delay in the arrival of a hydrograph mass center, as rainfall mass center tends to be located closer to the headwater of the basin. Mejía and Moglen (2010) investigated the flood response to the distribution of impervious surface by partitioning rainfall excess generation to pervious and impervious areas of a catchment. The study concluded that the imperviousness pattern is important when it is collocated with the mass center of rainfall.

Viglione et al. (2010a) generalized the Woods and Sivapalan (1999) framework by relaxing the "stationary rainfall" assumption. Their framework has terms to describe the relative movement of rainfall to the other variables. Viglione et al. (2010b) utilized their generalized framework to study the relative importance among rainfall space-time processes in controlling runoff generation for different types of floods. The study pointed out that the space and time covariance are important in runoff generation for short-duration rainfall events due to their highly localized feature; the spatial covariance is irrelevant for long-duration rainfall events since the rainfall field tends to be uniformly distributed over the catchment. Zoccatelli et al. (2011) derived the spatial moment of catchment rainfall and catchment scale storm velocity under the constant runoff coefficient assumption. The results indicate that the closer the rainfall mass center is to the catchment outlet, the earlier the arrival of the hydrograph mass center is. This aspect was also revealed in the study of
Mei et al. (2014) that examined 164 (mostly moderate) flood events. The study further concluded that the shape of rainfall and its movement are relatively insensitive in shaping the event hydrograph mainly because of the unsaturated rainfall excess. Nikolopoulos et al. (2014) paid particular attention to the catchment-scale storm velocity and were able to demonstrate the scale dependency and rainfall intensity dependency to storm magnitude.

The Viglione et al. (2010a) analytical framework (hereafter referred to as V2010) is relevant to only one rainfall excess (event flow) component. In this sense, the different runoff generation processes associated with vertical heterogeneous catchment layers are lumped together into a single flood response (Woods and Sivapalan, 1999; Viglione et al., 2010b). Numerous experimental studies, though, have demonstrated that catchment flood response can be identified as multiple components originating from different catchment layers and associated with different flow paths (Weiler et al., 2003; Liu et al., 2004; Gonzales et al., 2009). This is also prescribed in distributed hydrologic model where rainfall excess is often partitioned into different linear reservoirs representing different routing mechanisms (Koren et al., 2004; Blöschl et al., 2008; Wang et al., 2011). Thus, we see the necessity of further generalizing V2010 to represent multicomponent flood responses. The analytical framework presented in this paper is visualized in Fig. 1. Catchment rainfall forcing is converted to more than one rainfall excess component associated with various surface and subsurface layers. These rainfall excess components are subjected to different flow paths and routing schemes. The output hydrograph is a combination of hydrographs from the different components. A point to note is that our discretization of streamflow is still within the context of event flow and is not extended to the very slow response (e.g., baseflow). To sum up, our expanded framework introduces parallel channels to represent the different components of catchment flood response. This new capability relative to V2010 and other previous frameworks can support studies to help us understand which space-time process 
is the most dominant for a component of catchment response and how the contributions of different rainfall excess components are changing across disparate hydrologic regimes (basin scales, rainfall duration, and space-time distribution, etc.).

We illustrate the multicomponent flood response framework based on a two-component assumption consistent with a distributed hydrologic model structure. The illustration is built based on a relatively large number of rainfall-runoff events from three catchments in the Tar River basin in North Carolina. The paper is organized as follows. In Sect. 2, the study basin and data used in the study are described. Section 3 illustrates the experimental design with the hydrologic model. The analytical framework equations together with the demonstrations are presented in Sect. 4. Tests to understand the framework sensitivity to flood characteristics are provided in Sect. 5. Conclusions (including limitations and future works) are discussed in Sect. 6.

\section{Study area and dataset}

\subsection{Tar River basin and hydrometeorology data}

We conducted our analysis over three nested catchments (namely Swift, Fishing and Tar) in the Tar River basin, a lowelevation basin located in North Carolina (maximum elevation is $220 \mathrm{~m}$ a.s.1. - above sea level). The study catchment areas are 426,1374 , and $2406 \mathrm{~km}^{2}$, characterized by mild slopes (mean slope at $0.90,0.81$, and $0.83 \%$, respectively). The prevailing climate of the area is humid subtropical, causing annual precipitation and runoff around 1100 and $250 \mathrm{~mm}$, respectively. The reader is referred to Mei and Anagnostou (2015) and Mei et al. (2014) for details on the hydrology of the study area.

The stage 4 radar-based multi-sensor precipitation estimates (STIV hereafter) from the National Center for Environmental Prediction is used as our reference rainfall (Lin, 2011). The product is mosaicked from the Regional Multisensor Precipitation Analysis (RMPA) produced by the National Weather Service River Forecast Centers and benefits from some manual quality control process (Lin and Mitchell, 2005). The RMPA includes rain rates from merged operational radar estimates (150 Doppler Next-Generation Weather Radar) and 5500 hourly rain gauge measurements. The STIV data are hourly and available at approximately $4 \mathrm{~km}$ spatial resolution. The data used in this study have been spatially interpolated to $1 \mathrm{~km}$ by the bilinear method. Another atmospheric forcing dataset used in this study is the potential evapotranspiration (PET), available from the North American Regional Reanalysis (NARR) at 3-hourly and $32 \mathrm{~km}$ resolution (Mesinger et al., 2006). The NARR PET product accounts for evaporation from the soil, transpiration from the vegetation canopy, evaporation of dew and frost or canopy-intercepted precipitation, and snow sublima- tion. We also used hourly flow rates that were aggregated from the $15 \mathrm{~min}$ flow rate records available from the United States Geology Survey (USGS) for the three study catchments.

\subsection{Rainfall-runoff event selection}

The study rainfall-runoff events are extracted from the observation datasets using the characteristic point method (CPM) introduced in Mei and Anagnostou (2015). The advantages of CPM are its parsimonious data requirement (basin area and time series of rainfall and flow) and automatic extraction of events based on time series features. Event runoff and rainfall periods are identified from the long-term continuous time series of observed flow and rainfall records. Rainfall periods satisfying the following conditions are associated with each of the flood periods:

- rainfall period(s) occurring before the flood period but within the time of concentration of the basin;

- rainfall period(s) located on the rising limb of the flood period; and

- rainfall period(s) occurring prior to the end of the flood period by a time length equal to the time of concentration.

All of the rainfall periods associated with the same flood period are integrated as one rainfall event and are considered as the inducing rainfall of the flood. Each of the rainfall and flood pairs forms a rainfall-runoff event. The CPM is applied on the USGS streamflow observations and catchmentaverage STIV rainfall data for the three study catchments. The method identified nearly 300 flood events from the study period, and these events were further filtered according to the hydrologic model performance as described in Sect. 3.2.

\section{Hydrologic model and experiment}

\subsection{Distributed hydrologic model}

The Coupled Routing and Excess STorage (CREST) model version 2.1 is used for the hydrologic simulations in our study (Shen and Hong, 2014). CREST is a fully distributed rainfall-runoff model designed to simulate flow discharges over watersheds at global scale. CREST integrates a water balance model for the vertical fluxes with a horizontal routing model for the surface and subsurface runoff (Wang et al., 2011; Shen, et al., 2016). The water balance model considers four processes: canopy interception, infiltration, evapotranspiration (ET), and runoff generation. The infiltration rate is calculated based on the variable infiltration curve developed in the Xinanjiang model (Zhao, 1992). For each grid cell, the actual ET (AET) is determined in terms of water and energy budget using precipitation, soil water availability, and 
PET. In the runoff generation process, CREST separates rainfall excess into two components, the surface and subsurface runoff modeled by two linear reservoirs - the overland and interflow reservoirs. In the routing process, the subgrid routing inhomogeneity is accounted for by employing these two runoff components. The model version used in this study implements the fully distributed linear reservoir routing method that overcomes the severe underestimation of flow in previous versions (Shen et al., 2016). The parameter optimization algorithm adapted in CREST is the shuffled complex evolution (SCE-UA) developed by Duan et al. (1992).

\subsection{Experimental design}

As a first step, the model is set up over the three study catchments with $1 \mathrm{~km}$ spatial resolution. The geomorphologic and hydrologic variables (i.e., flow direction, flow accumulation, slope, and stream channel) of the catchment areas are provided by the Hydrological data and maps based on SHuttle Elevation Derivatives at multiple Scales (HydroSHEDS) (Lehner et al. 2008). The STIV precipitation and NARR PET product force the model to compute the through precipitation, actual evapotranspiration, infiltration capacity, soil water content, and rainfall excess. We keep the model setting relatively simple by "turning off" the canopy interception, meaning that the process is conceptualized by a multiplier of the precipitation data, which is optimized by a calibration process. In addition, the fraction of impervious surface in this study is represented by an imperviousness parameter that was optimized through model calibration. The model was calibrated in the three catchments with respect to the observed hourly flow rate from 2004 to 2006 (the years 2002 to 2003 are used as the spinning period). The Nash-Sutcliffe coefficients of efficiency (NSCEs) of the flow simulations in the Swift, Fishing, and Tar catchments determined at hourly scale are $0.69,0.62$, and 0.66 , respectively, indicating reasonable performance of the model over the study catchments (Moriasi et al., 2007).

Rainfall-runoff events from the 2003 to 2012 period with duration shorter than $500 \mathrm{~h}$ are identified from the continuous flow simulations during the time periods provided by the CPM. The mean error (ME), correlation coefficient (CC), and NSCE are calculated with respect to the observed flow rate for each event and these error metrics are ranked in ascending order (consider only the magnitude when ranking ME). Flood events of ME higher than the 95th percentile and CC and NSCE lower than their respective 5th percentile were discarded from the analysis to keep our results representative in the context of hydrologic simulation. These selection criteria resulted in 180 events $(62,57$, and 61 events, respectively, for the smallest to largest catchments) with overall relative centered root mean square error being equal to 42.0 , 43.0 , and $34.4 \%$, respectively. Two pilot events used in the framework demonstrations are exhibited in Fig. 2. They are characterized by high $\mathrm{CC}$ and low relative centered root mean square (CRMS) values with respect to the observed flow time series. The $\mathrm{CC}$ for the two events are above 0.94 and 0.82 with relative CRMS at about $50 \%$ (Swift catchment for event 2 is an exception with CRMS at about $100 \%$ ). The first is an intermittent event that lasted for $93 \mathrm{~h}$ in June 2006; the second is a $66 \mathrm{~h}$ long event in November 2009. Mean rain rates (in $\mathrm{mm} \mathrm{h}^{-1}$ ) for the three catchments are 1.33, 0.87, and 1.31 for the first event and $1.34,1.22$, and 1.59 for the second event. It is noted that the concentration time increases as function of drainage area. The rainfall mass that triggered the June 2006 event is distributed around the outlet while the November 2009 event is spatially bimodal.

Our last step is to remove the influences of the non-zero initial condition of each event in the continuous simulations. For each event period, we run CREST by setting both rainfall and PET data to zero so as to output the "baseflow hydrograph". This baseflow hydrograph gives or mimics the recession of flow with the initial condition over the event time period. The event flow hydrographs are subtracted by the baseflow hydrographs and the new event flow hydrographs are obtained for the subsequent analysis.

\section{Analytical framework of catchment response}

The V2010 analytical framework quantifies the effects of spatiotemporal variability of rainfall, runoff generation, and routing on a basin's flood response. The follow-up application by Viglione et al. (2010b) isolated the event flow component from baseflow, simulated using the Kamp model, and demonstrated the magnitudes of terms of catchment spacetime processes represented in V2010. In our study, we extend the V2010 framework with the consideration that event flow consists of multiple components from the vertical layers of catchment (Fig. 1). We illustrate the new framework using a two-component (surface and subsurface) flow generation process, consistent with the overland and interflow reservoir of CREST. Similar to V2010, our analytical framework estimates catchment response by three quantities: (a) the amount of rainfall excess, (b) the mean catchment response time, and (c) the variance of catchment response time. These three quantities are proxies of the corresponding flood characteristics, namely (a) the cumulative event flow volume, (b) the hydrograph centroid, and (c) the spreadness of hydrograph. A two-stage framework structure that decomposes the catchment response to rainfall excess generation and runoff routing is adopted (Mejía and Moglen, 2010; Zoccatelli et al., 2011; Mei et al., 2014). Although a more detailed multi-stage framework could increase the rational of modeling (Zoccatelli et al., 2015), in this study, we considered the hillslope and channel routing processes as part of the runoff routing (described later in Eq. 3). Specifically, we focus on deriving the analytical framework equations under the multicomponent scenario described in Sect. 4.2 and 4.3. The variables used in the framework (rainfall, runoff coefficient, and runoff 

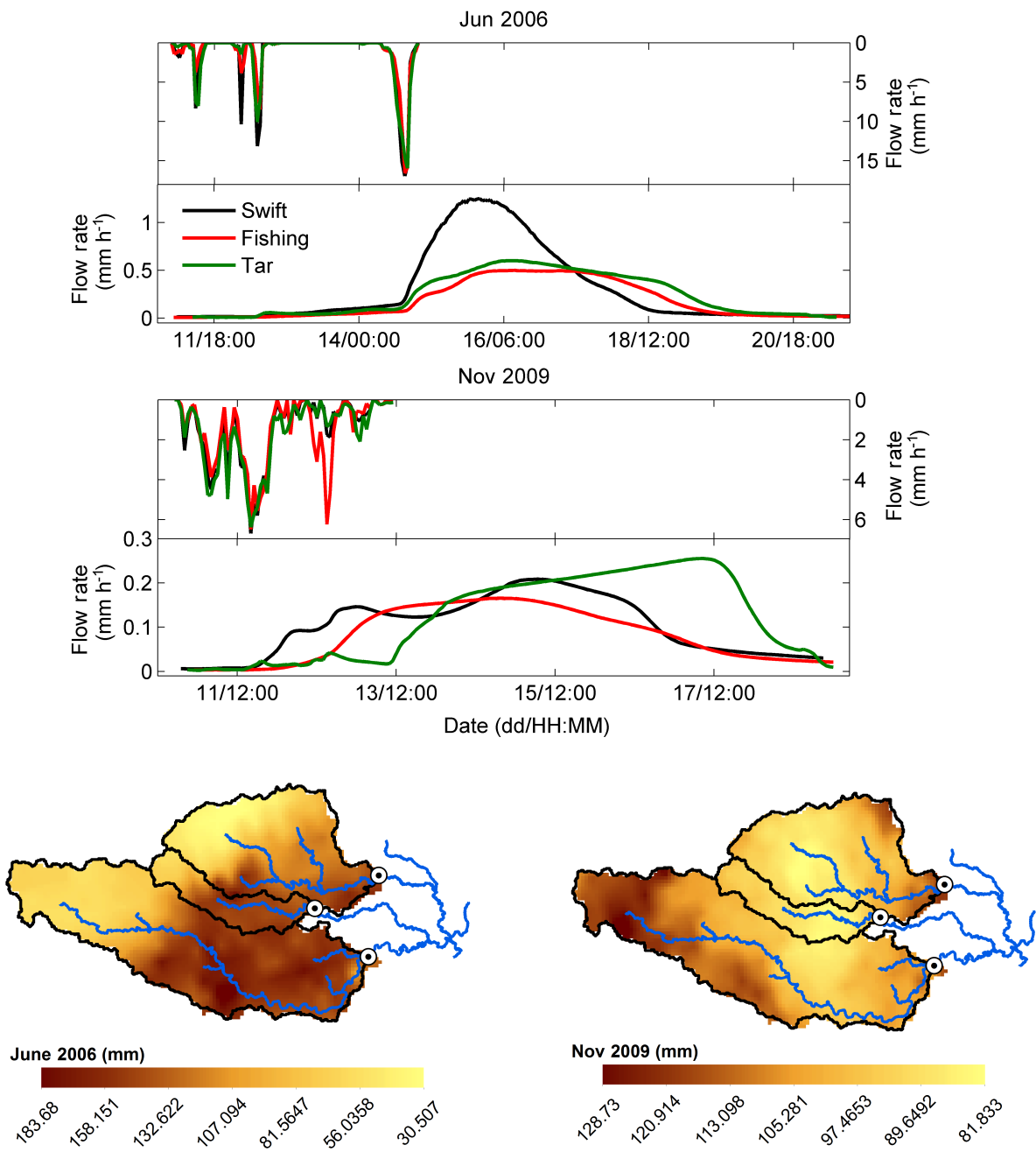

Figure 2. Event rainfall map and time series of rainfall and runoff for the two representative events.

routing time) are attained from the CREST model parameters and are described in Sect. 4.1.

\subsection{Analytical framework variables}

The analytical framework has three input variables - the rainfall, the runoff coefficient, and the runoff routing time. The rainfall variable for the framework refers to the net amount of precipitation that reaches the catchment surface after actual evaporation loss and vegetation intercepted rainfall is subtracted and its partition in surface and subsurface runoff. The rainfall variable, $P(a, t)$, is determined in this study as

$P(a, t)=C_{\mathrm{I}} P^{\prime}(a, t)-E_{\mathrm{a}}(a, t)$,

where $P^{\prime}(a, t)$ and $E_{\mathrm{a}}(a, t)$ are actual precipitation (STIV precipitation) and evaporation rates (calculated by CREST in this study). Indexes $a$ and $t$ stand for the location and time dimensions. $C_{\mathrm{I}}$ is the multiplier that conceptualizes the canopy.

Most distributed hydrologic models separate the rainfall excess into two components - the surface and the subsur- face rainfall excess - and route them by two parallel flow paths with different speeds and outflow rates. Namely, the flood response for catchment surface and subsurface are associated with different generations and routing mechanisms characterized by different runoff coefficients and runoff routing time. The surface process is intimately related to the fraction of impervious surface over the basin where the throughrainfall is converted to rainfall excess, which can be represented as a uniform parameter, $I_{\mathrm{M}}$, optimized through the hydrologic model calibration. Thus, the surface runoff coefficient, $W_{2}(a, t)$, is represented in the proposed framework by the imperviousness parameter, $I_{\mathrm{M}}$. Values of $I_{\mathrm{M}}$ for the three catchments (from small to large) are 13.1, 10.9, and $11.3 \%$. On the other hand, the amount of runoff generated from the subsurface is positively correlated to the soil wetness based on the variable infiltration curve adopted by CREST. Thus, the subsurface runoff coefficient, $W_{1}(a, t)$, is estimated as

$W_{1}(a, t)=\frac{\operatorname{SM}(a, t)}{W_{\mathrm{M}}}$, 

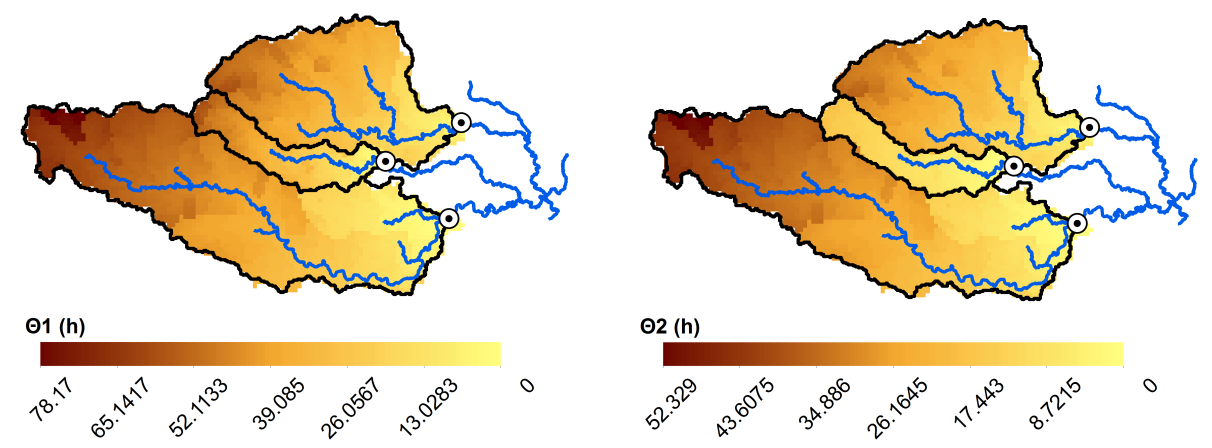

Figure 3. Runoff routing time for the study basins.

where $\operatorname{SM}(a, t)$ is the volumetric soil moisture (one of the model outputs), and $W_{\mathrm{M}}$ is the maximum water capacity calibrated from the model. Overall, $W_{\mathrm{M}}$ increases from the smallest to the largest basin (values are 106, 198, and $249 \mathrm{~mm}$ ).

For runoff routing, CREST modeled the basin surface as hillslope and channel grids with different concentration times. The concept of concentration time is a measurement of the required time for the rainfall excess to drain from its originating grid to the next downstream grid. Traveling time of water from a given grid cell is calculated as the summation of all the concentration time along its flow path to the basin outlet. Therefore, the runoff routing time is written as

$\Theta(a)=\alpha[\underbrace{\sum_{L_{\mathrm{h}}(a)} \frac{l(a)}{s(a)^{\beta}}}_{\text {Hillslope }}+\underbrace{\frac{1}{K} \sum_{L_{\mathrm{c}}(a)} \frac{l(a)}{s(a)^{\beta}}}_{\text {Channel }}]$,

where $l(a)$ and $s(a)$ are the length of flow path from a grid to its adjacent downstream grid and the slope at that grid, respectively; $L_{\mathrm{h}}(a)$ and $L_{\mathrm{c}}(a)$ represent the space of hillslope and channel flow path from a grid cell to the catchment outlet; $K$ is the overland runoff velocity coefficient used to distinguish hillslope routing to channel routing; $\beta$ is the flow speed exponent. Although hillslope and channel routing times are modeled by the same method, they differ by the length of the respective flow paths and velocity; the sum of these two routing times yields the runoff routing time. The term $\alpha$ is a velocity coefficient that is used to distinguish the surface and subsurface routing. In our study, $\alpha$ is unity in Eq. (3) for the subsurface runoff routing time, $\Theta_{1}(a)$; it takes values smaller than 1 to represent $\Theta_{2}(a)$, the surface runoff routing time, since surface routing should be faster than subsurface routing. Values of $\alpha$ are $0.31,0.63$, and 0.67 for the study catchments. Therefore, routing times for the surface and subsurface processes are proportional to each other:

$\frac{\Theta_{2}(a)}{\Theta_{1}(a)}=\alpha$
Magnitudes of the spatially variable runoff routing time for the surface and subsurface processes are illustrated in Fig. 3. The figure shows that runoff routing time increases going upstream. The Tar catchment (the largest one) is characterized by the widest value range compared to the other two subbasins. The Swift catchment shows distinctively lower overall values for the surface runoff routing time $\left(\Theta_{2}\right)$ due to its low $\alpha$ value ( 0.3 compared to above 0.6 for the other two). This is expected given that model parameters of the three catchments are independently calibrated.

\subsection{Generation of rainfall excess}

The generation of rainfall excess at location and time $(a, t)$ is calculated as

$R_{i}=P W_{i}$,

where $R_{i}, P$, and $W_{i}$ are the space-time variable rainfall excess, precipitation, and runoff coefficient field. Index $i$ indicates different rainfall excess components generated from the different vertical layers of surface and subsurface. In this study, we used two layers ( $i=1$ and 2 ) to denote the subsurface and surface rainfall excess, respectively. The total rainfall excess is the summation of all the rainfall excess components:

$R=P \sum_{i=1}^{N} W_{i}$.

Note that the sum of all $W_{i}$ is the total runoff coefficient $W$. To calculate the instantaneous basin-average rainfall excess, we take the spatial expectation of Eq. (6):

$[R]_{\mathrm{a}}=[P]_{\mathrm{a}} \sum_{i=1}^{N}\left[W_{i}\right]_{\mathrm{a}}+\left\{P, \sum_{i=1}^{N} W_{i}\right\}$,

where []$_{\mathrm{a}}$ and \{\}$_{\mathrm{a}}$ stand for the expectation and covariance (variance if the variables are the same) operator applied over the catchment area. The distributed storm-average rainfall excess is given by taking the temporal expectation of Eq. (6):

$[R]_{\mathrm{t}}=[P]_{\mathrm{t}} \sum_{i=1}^{N}\left[W_{i}\right]_{\mathrm{t}}+\left\{P, \sum_{i=1}^{N} W_{i}\right\}$. 


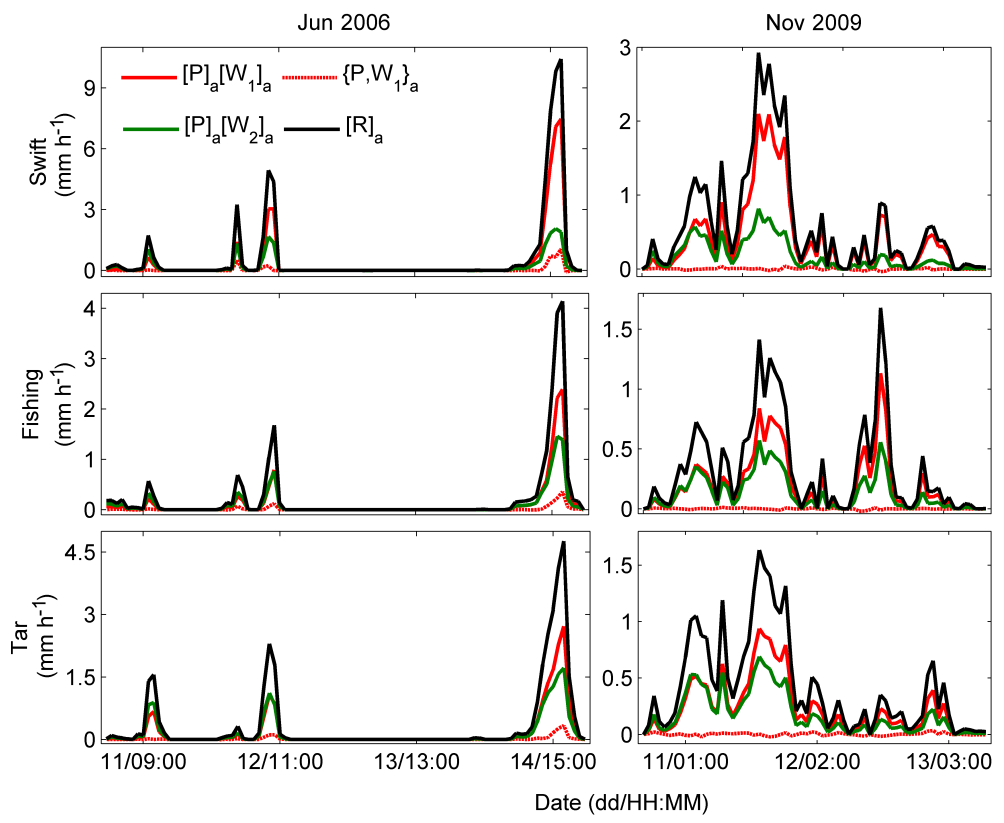

Figure 4. Time series showing the spatial averaged terms in Eq. (7) for the different rainfall excess components of the two representative events.

The first term in Eqs. (7) and (8) is the product between spatial or temporal average rainfall and runoff coefficient, while the second term quantifies the spatial or temporal variability between rainfall and runoff coefficient at every time step/catchment grid.

Figures 4 and 5 show the magnitudes of the different terms of Eq. (7) and (8), respectively. Note that since the surface runoff coefficient $W_{2}$ is estimated as a space-time constant, the space and time covariance term between $W_{2}$ and $P$ (i.e., $\left\{P, W_{2}\right\}_{\mathrm{a}}$ and $\left.\left\{P, W_{2}\right\}_{\mathrm{t}}\right)$ are 0 and are not shown. It is noted from Fig. 4 that the catchment-average rainfall excess $[R]_{\mathrm{a}}$ is strongly correlated to the catchment-average rainfall $\left([P]_{\mathrm{a}}\right.$ shown in Fig. 2) mainly because of the spatial covariance term $\left\{P, W_{1}\right\}_{\mathrm{a}}$ that is irrelevant to $[R]_{\mathrm{a}}$. This low magnitude of $\left\{P, W_{1}\right\}_{\mathrm{a}}$ indicates that rainfall and runoff coefficients are not collocated in space for the two pilot events. Meanwhile, the relative importance between $[P]_{\mathrm{a}}\left[W_{1}\right]_{\mathrm{a}}$ and $[P]_{\mathrm{a}}\left[W_{2}\right]_{\mathrm{a}}$ changes dynamically throughout the event where $[P]_{\mathrm{a}}\left[W_{1}\right]_{\mathrm{a}}$ and $[P]_{\mathrm{a}}\left[W_{2}\right]_{\mathrm{a}}$ are comparable during the early phase but $[P]_{\mathrm{a}}\left[W_{1}\right]_{\mathrm{a}}$ overwhelms in the mature and decaying phase of the event. This is attributed to the dynamics of $\left[W_{1}\right]_{a}$ and $\left[W_{2}\right]_{\mathrm{a}}$ during the event, as shown by the differences between $\left[W_{1}\right]_{\mathrm{a}}$ and $\left[W_{2}\right]_{\mathrm{a}}$ on the top two panels of Fig. 6. During the evolution of the event, $\left[W_{1}\right]_{\mathrm{a}}-\left[W_{2}\right]_{\mathrm{a}}$ start negative and change to positive, reflecting the increase in subsurface runoff coefficient $\left[W_{1}\right]_{\mathrm{a}}$ due to the increase in wetness condition of the catchment. This dynamic change in $\left[W_{1}\right]_{\mathrm{a}}$ and $\left[\mathrm{W}_{2}\right]_{\mathrm{a}}$ also demonstrates why the surface rainfall excess component is the quick response from the model. In addition, the differences between $\left[W_{1}\right]_{\mathrm{a}}$ and $\left[W_{2}\right]_{\mathrm{a}}$ of the Swift catchment are noticeably larger than the other two catchments in Fig. 6; this could be attributed to the lower maximum water capacity of the Swift catchment compared to the other two.

Figure 5 illustrates the temporal aggregated maps for terms in Eq. (8). The products between temporal average rainfall and runoff coefficient (i.e., $[P]_{\mathrm{t}}\left[W_{1}\right]_{\mathrm{t}}$ and $[P]_{\mathrm{t}}\left[W_{2}\right]_{\mathrm{t}}$ ) account for the major contribution of the storm-average rainfall excess. The product term $[P]_{\mathrm{t}}\left[W_{1}\right]_{\mathrm{t}}$ is generally larger than $[P]_{\mathrm{t}}\left[W_{2}\right]_{\mathrm{t}}$ because $\left[W_{1}\right]_{\mathrm{t}}$ is larger than $\left[W_{2}\right]_{\mathrm{t}}$, as shown in the bottom two panels of Fig. 6. This is exemplified for the Swift catchment due to its lower maximum water capacity. The temporal covariance between rainfall and subsurface runoff coefficient, $\left\{P, W_{1}\right\}_{\mathrm{t}}$, is higher for the June 2006 event that exhibits more distinct rainfall bursts and for the Swift catchment, where $W_{1}$ is more sensitive to rainfall dynamics.

The temporal or spatial integration of Eqs. (7) and (8) yields the catchment-average storm rainfall excess, $[R]_{\text {at }}$ (see Appendix A for details):

$$
\begin{aligned}
{[R]_{\mathrm{at}} } & =\underbrace{[P]_{\mathrm{at}} \sum_{i=1}^{N}\left[W_{i}\right]_{\mathrm{at}}}_{R 1}+\underbrace{\left\{[P]_{\mathrm{a}} \sum_{i=1}^{N}\left[W_{i}\right]_{\mathrm{a}}\right]_{\mathrm{t}}}_{R 2}+\underbrace{\left\{[P]_{\mathrm{t}} \sum_{i=1}^{N}\left[W_{i}\right]_{\mathrm{t}}\right\}_{\mathrm{a}}}_{R 3} \\
& +\underbrace{\left[\left\{\left(P-[P]_{\mathrm{t}}\right), \sum_{i=1}^{N}\left(W_{i}-\left[W_{i}\right]_{\mathrm{t}}\right)\right\}_{\mathrm{a}}\right]_{\mathrm{t}}}_{R 4}
\end{aligned}
$$

where [ $]_{\text {at }}$ is the space-time aggregation on the catchment area and event period. This equation indicates that the amount of total catchment-average storm rainfall excess is the sum of catchment-average storm rainfall excess from all 

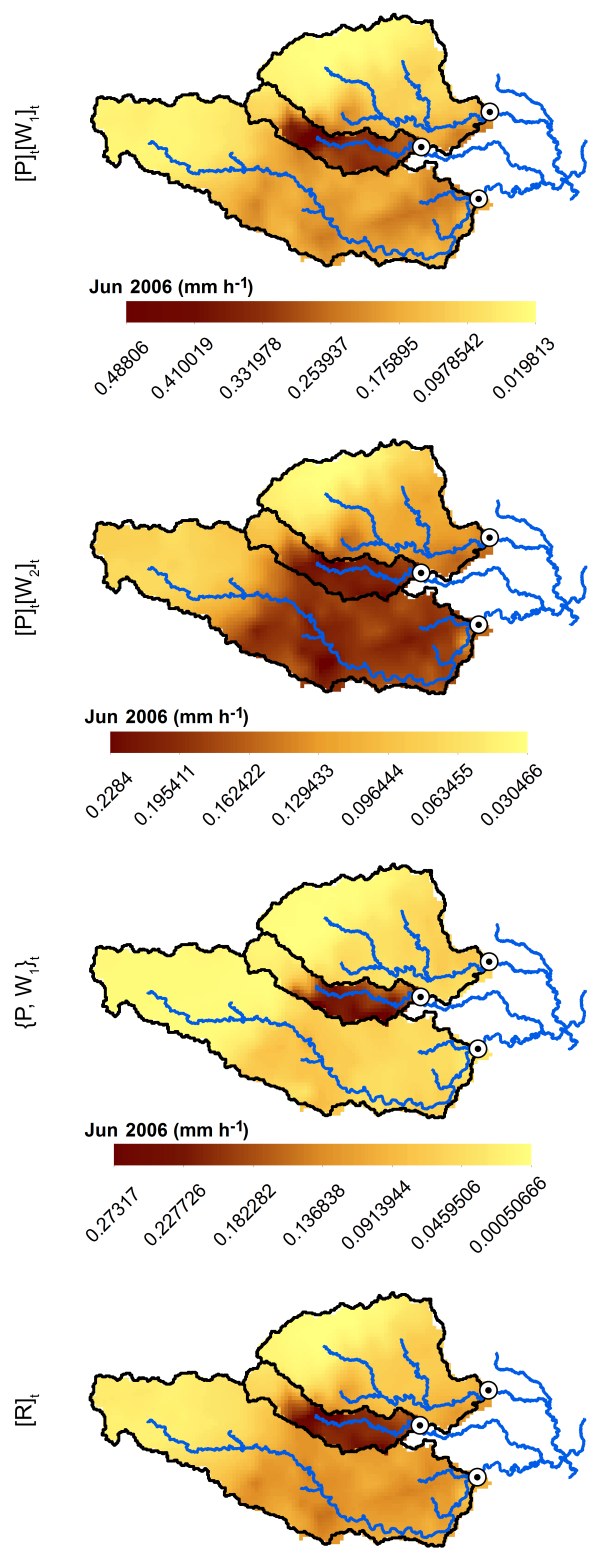

$$
\begin{aligned}
& \text { Jun } 2006\left(\mathrm{~mm} \mathrm{~h}^{-1}\right)
\end{aligned}
$$

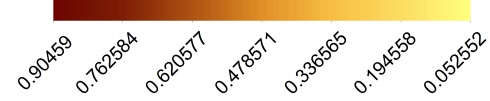

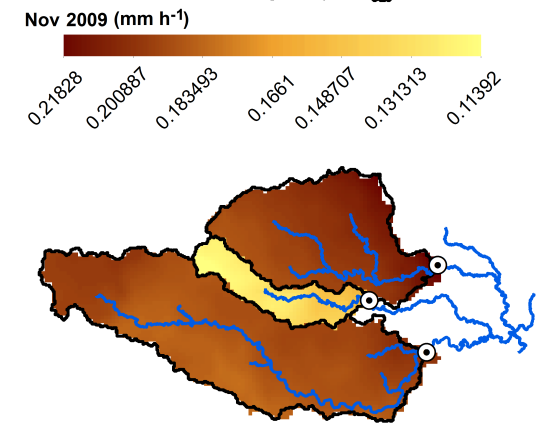

Nov $2009\left(\mathrm{~mm} \mathrm{~h}^{-1}\right)$
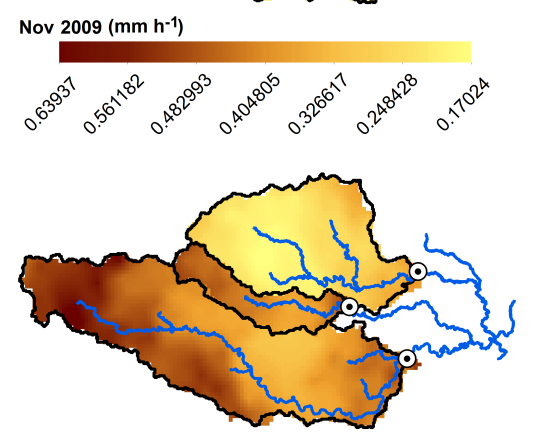

Nov $2009\left(\mathrm{~mm} \mathrm{~h}^{-1}\right)$
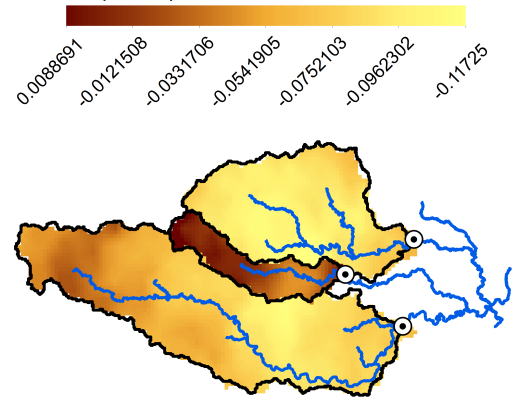

Nov $2009\left(\mathrm{~mm} \mathrm{~h}^{-1}\right)$

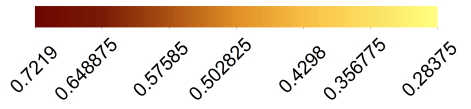

Figure 5. The same as Fig. 4 but for temporal averaged terms in Eq. (8).

components. Term $R_{1}$ represents the sum of product between the catchment-average storm rainfall and runoff coefficient for all components. Terms $R_{2}$ and $R_{3}$ are the sum of tempo$\mathrm{ral} / \mathrm{spatial}$ covariance between the catchment-/storm-average rainfall and runoff coefficient. $R_{4}$ is the sum of temporal covariance between spatial variation of precipitation and runoff coefficient. Moreover, V2010 has shown that the effect of storm movement can be isolated as $R_{4}-R_{2} \cdot R_{3} / R_{1}$. This movement effect is also studied later.
The magnitudes of terms in Eq. (9) along with the movement effect (MV) for the study events are illustrated in Fig. 7 with statistics summarized in Table 1 (the two sample events are highlighted in the figure). Note that the $R_{2}, R_{3}, R_{4}$, and MV for the surface component are 0 due to the space-time constant surface runoff coefficient and thus are not shown. A term-wise comparison shows clearly that $R_{1}$ is the most dominant contributor to $[R]_{\mathrm{at}}$. The figure and table reveal that the spatial and temporal correlation between rainfall and runoff coefficients is almost negligible. This is consistent with the 

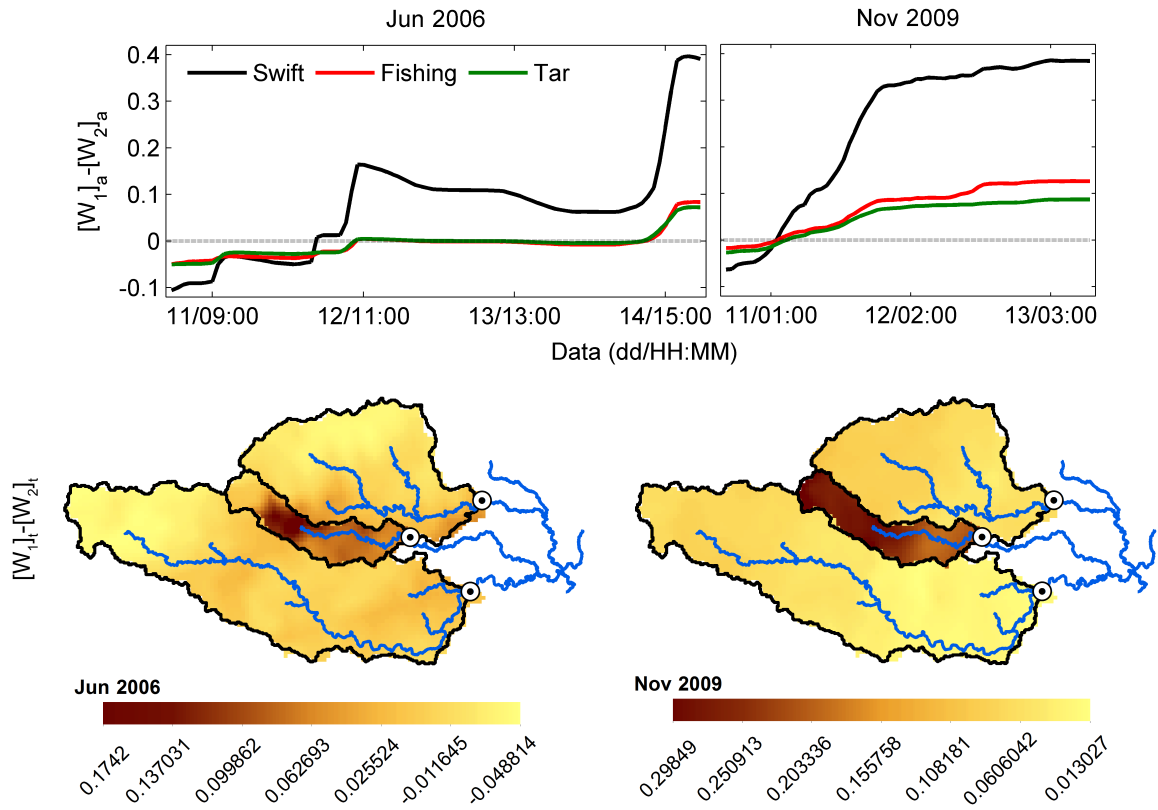

Figure 6. Differences between catchment-average and storm-average runoff coefficient.

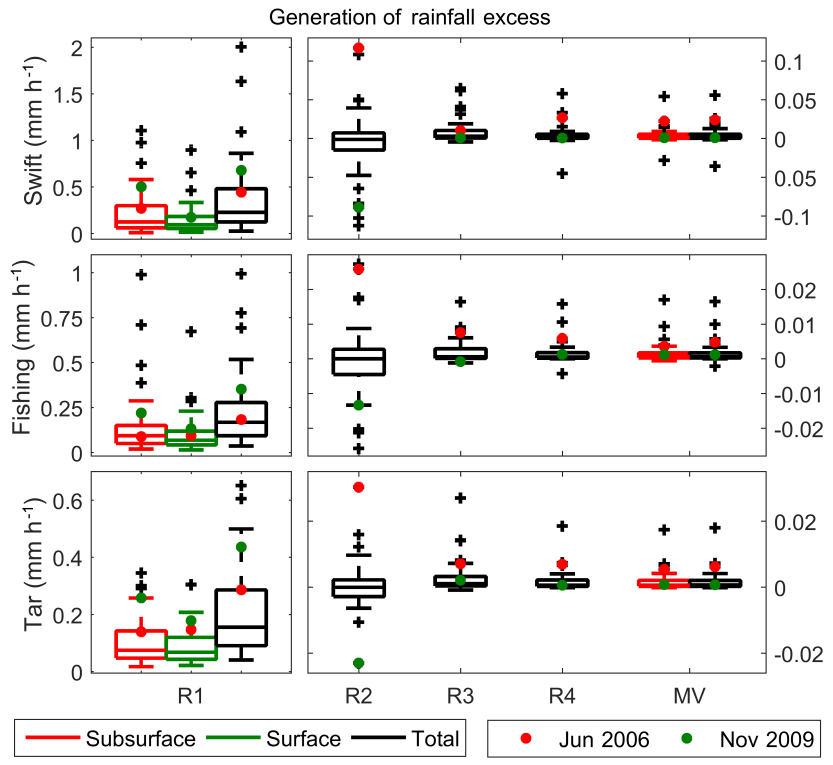

Figure 7. Boxplot showing the spatiotemporal averaged terms in Eq. (9) based on all events from the study basins.

previous studies which show generally low magnitudes of the $R_{2}, R_{3}$, and $R_{4}$ but high $R_{1}$ (Viglione et al., 2010b; Mejía and Moglen, 2010). The relatively low magnitudes of term $\left\{P, W_{1}\right\}_{\mathrm{a}}$ and $\left\{P, W_{1}\right\}_{\mathrm{t}}$ in Figs. 4 and 5 also agree with this observation. The fairly low magnitudes of space and time covariance will lead to an insignificant movement effect (mean at $10^{-3} \mathrm{~mm} \mathrm{~h}^{-1}$ from Table 1 ). Investigation on $R_{1}$ (the most significant term) shows a decrease in magnitude with basin scale. This dampening effect has different reasons for the two rainfall excess components. For the surface component, the diminishing magnitude with increase in scale is a result of the decrease in catchment-average rainfall given that $W_{2}$ is constant among catchments. For the subsurface process, this is due to both the decrease in runoff coefficient and catchmentaverage rainfall. Moreover, Table 1 reveals that the subsurface component generally outperforms the surface component in contribution to $R_{1}$. Yet these magnitude differences are diminishing from the smallest to the largest catchment since the gap between $W_{1}$ and $W_{2}$ is narrowing.

\subsection{Catchment response time}

The catchment response is conceptualized by two stages rainfall on the catchment and a portion of it turning into rainfall excess; then, the rainfall excess is routed to the catchment outlet (Zoccatelli et al., 2011; Mei et al., 2014). These two stages are associated with their own "holding times" which are treated as random variables (Rodríguez-Iturbe and Valdés, 1979). The catchment response time is the sum of these two holding times and thus is also a random variable. It measures the time needed from the beginning of a storm to a drop of rainwater exiting the catchment outlet, whose probability distribution function (PDF) for the $i$ th rainfall excess component, $f_{\mathrm{R}_{i}}$, is

$f_{\mathrm{R}_{i}}=\frac{R_{i}}{\left[R_{i}\right]_{\mathrm{at}}}$.

Note that $f_{\mathrm{R}_{i}}$ is a space-time variable. Thus, the PDF for total rainfall excess, $f_{\mathrm{R}}$, can be written as 
Table 1. Mean magnitudes of terms in Eq. (9) in $\mathrm{mm} \mathrm{h}^{-1}$.

\begin{tabular}{|c|c|c|c|c|c|c|c|c|c|}
\hline \multirow[t]{2}{*}{ Term } & \multicolumn{3}{|c|}{ Swift } & \multicolumn{3}{|c|}{ Fishing } & \multicolumn{3}{|c|}{ Tar } \\
\hline & Subsurface & Surface & Total & Subsurface & Surface & Total & Subsurface & Surface & Total \\
\hline$R_{1}$ & 0.212 & 0.149 & 0.361 & 0.138 & 0.100 & 0.238 & 0.103 & 0.088 & 0.193 \\
\hline$R_{2}$ & -0.005 & - & -0.005 & -0.001 & - & -0.001 & 0.000 & - & 0.000 \\
\hline$R_{3}$ & 0.011 & - & 0.008 & 0.005 & - & 0.005 & 0.004 & - & 0.004 \\
\hline$R_{4}$ & 0.004 & - & 0.005 & 0.001 & - & 0.001 & 0.002 & - & 0.002 \\
\hline$R_{\mathrm{at}}$ & 0.222 & 0.149 & 0.371 & 0.144 & 0.100 & 0.243 & 0.108 & 0.090 & 0.198 \\
\hline MV & 0.005 & - & 0.005 & 0.001 & - & 0.001 & 0.002 & - & 0.002 \\
\hline
\end{tabular}

$f_{\mathrm{R}}=\sum_{i}^{N} \psi_{i} f_{\mathrm{R}_{i}}$

where $\psi_{i}$ is the rainfall excess ratio defined as the ratio of catchment-average storm rainfall excess for a component to that for the total rainfall excess:

$\psi_{i}=\frac{\left[R_{i}\right]_{\mathrm{at}}}{[R]_{\mathrm{at}}}$.

The sum of $\psi_{i}$ goes up to 1 by definition. Equation (11) shows that the PDF of catchment response time is a convex combination for each PDF of the rainfall excess component.

\subsubsection{Expectation of catchment response time}

For the two-stage analytical framework in this study, the expectation of catchment response time $E\left(T_{q}\right)$ can be decomposed to the expectation of holding time of the two stages:

$E\left(T_{q}\right)=\underbrace{E\left(T_{\mathrm{r}}\right)}_{\text {Stage1 }}+\underbrace{E\left(T_{\mathrm{n}}\right)}_{\text {Stage } 2}$,

where $T_{\mathrm{r}}$ and $T_{\mathrm{n}}$ correspond to the rainfall excess generation time and runoff routing time. The rainfall excess generation time is represented by the instantaneous time, $T$. Thus, the expected rainfall excess generation time, $E_{i}\left(T_{\mathrm{r}, i}\right)$, for any component is provided as (see Appendix B)

$E_{i}\left(T_{\mathrm{r}, i}\right)=\frac{\left|T_{\mathrm{P}}\right|}{2}+\frac{\left\{T,\left[R_{i}\right]_{\mathrm{a}}\right\}_{\mathrm{t}}}{\left[R_{i}\right]_{\mathrm{at}}}$,

where $\left|T_{\mathrm{P}}\right|$ is the duration of the rainfall event. $E_{i}\left(T_{\mathrm{r}, i}\right)$ is a measurement of the temporal mass center of rainfall excess. If the rainfall mass is symmetric with respect to its midpoint, the half-duration is sufficient to describe the expectation of rainfall excess generation. Following the distribution function of Eq. (11), we derived the expected rainfall generation time for total rainfall excess $E\left(T_{\mathrm{r}}\right)$ as (see Appendix B for the derivation)

$E\left(T_{\mathrm{r}}\right)=\sum_{i}^{N} \psi_{i} E_{i}\left(T_{\mathrm{r}, i}\right)$.

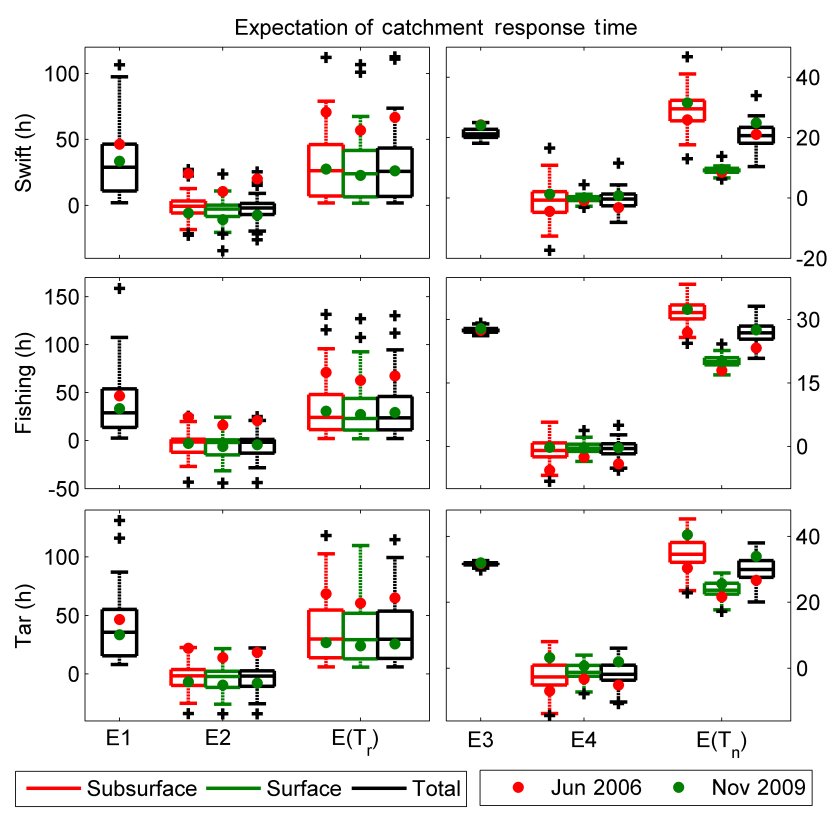

Figure 8. The same as Fig. 7 but for Eqs. (16) and (23).

Equation (15) indicates that the temporal mass center of total rainfall excess is a linear combination (or the expectation) of the mass centers of all the other rainfall excess components with respect to the rainfall excess ratio. The equation also implies that the larger the magnitude of a component, the greater impact it has on the timing of the total rainfall excess. Substituting Eqs. (12) and (14) into Eq. (15), we have

$E\left(T_{\mathrm{r}}\right)=\underbrace{\frac{\left|T_{\mathrm{P}}\right|}{2}}_{E 1}+\underbrace{\frac{\left\{T, \sum_{i}^{N}\left[R_{i}\right]_{\mathrm{a}}\right\}}{[R]_{\mathrm{at}}}}_{E 2}$.

$E_{1}$ refers to the event half-duration and $E_{2}$ is the expectation of time distance from the event midpoint to the temporal mass center of catchment-average rainfall excess.

The magnitudes of terms in Eq. (16) are illustrated in Fig. 8 (left panel) and summarized in Table 2 (first three rows). At a first glance, the expectation of catchment re- 
Table 2. The same as Table 1 but for Eqs. (16) and (23).

\begin{tabular}{|c|c|c|c|c|c|c|c|c|c|}
\hline \multirow[t]{2}{*}{ Term } & \multicolumn{3}{|c|}{ Swift } & \multicolumn{3}{|c|}{ Fishing } & \multicolumn{3}{|c|}{ Tar } \\
\hline & Subsurface & Surface & Total & Subsurface & Surface & Total & Subsurface & Surface & Total \\
\hline$E_{1}$ & 32 & 32 & 32 & 38 & 38 & 38 & 40 & 40 & 40 \\
\hline$E_{2}$ & -0.78 & -4.5 & -2.3 & -4.3 & -6.3 & -5.1 & -2.0 & -4.1 & -3.0 \\
\hline$E\left(T_{\mathrm{r}}\right)$ & 32 & 28 & 30 & 33 & 31 & 32 & 38 & 36 & 37 \\
\hline$E_{3}$ & 30 & 9 & 21 & 33 & 20 & 27 & 37 & 25 & 32 \\
\hline$E_{4}$ & -1.2 & -0.22 & -0.64 & -1.0 & -0.37 & -0.68 & -2.6 & -1.2 & -1.8 \\
\hline$E\left(T_{\mathrm{n}}\right)$ & 29 & 9.2 & 21 & 32 & 20 & 27 & 35 & 24 & 30 \\
\hline$\psi$ & 0.57 & 0.43 & - & 0.57 & 0.43 & - & 0.54 & 0.46 & - \\
\hline$\xi$ & 0.70 & 2.27 & - & 0.84 & 1.34 & - & 0.85 & 1.27 & - \\
\hline$E\left(T_{q}\right)$ & 61 & 37 & 51 & 65 & 51 & 59 & 72 & 59 & 66 \\
\hline
\end{tabular}

sponse time is increasing with the basin area due to the increase in event duration. The magnitude of the half-duration is of more relevance to $E\left(T_{\mathrm{r}}\right)$, while the temporal covariance term can be an important contributor for a portion of events. This means that rainfall excess is not symmetric with respect to the event's midpoint. $E_{2}$ of the surface component is higher than the subsurface counterpart in magnitude. This is interpreted to mean that the surface rainfall excess preserves the temporal dynamics of catchment-average rainfall due to the constant runoff coefficient. On the other hand, for the subsurface component, the temporal characteristics of rainfall have been dampened through its interaction with runoff coefficients. This leads to a more symmetrically distributed time series based on the midpoint. Besides, Table 2 implies that the temporal locations of rainfall excess mass center appear earlier than the event's midpoint by rendering negative mean values of $E_{2}$. Lastly, we observe that the $E_{2}$ term of the June 2006 event is characterized by a larger value $(20 \mathrm{~h})$ than the other events (means of $E_{2}$ are all within $7 \mathrm{~h}$ in Table 2). This can be interpreted by its increasing trend in rain rate with time exhibited in the time series of Fig. 2.

Holding time for the runoff routing stage is modeled by the spatial variable runoff routing time $\left(\Theta_{i}\right)$ detailed in Sect. 4.1. The expectation of the runoff routing time, $T_{\mathrm{n}, i}$, for the rainfall excess component is derived as (Appendix C)

$E_{i}\left(T_{\mathrm{n}, i}\right)=\left[\Theta_{i}\right]_{\mathrm{a}}+\frac{\left\{\Theta_{i},\left[R_{i}\right]_{\mathrm{t}}\right\}_{\mathrm{a}}}{\left[R_{i}\right]_{\mathrm{at}}}$.

The first term stands for the catchment-average runoff routing time and the second term quantifies the delay in response due to spatial covariance between runoff routing time and storm-average rainfall excess. Analogously, we describe the relationship between $E_{i}\left(T_{\mathrm{n}, i}\right)$ and $E\left(T_{\mathrm{n}}\right)$. As a first step, an analytical relationship linking $\Theta_{i}$ and $\Theta$ together is required. Knowing that runoff routing time for the total rainfall excess should be between those for the slowest and fastest components, we assume $\Theta$ is a linear combination of all $\Theta_{i}$ with respect to the rainfall excess ratio $\psi_{i}$ :
$\Theta=\sum_{i}^{N} \psi_{i} \Theta_{i}$.

Under such an assumption, $\Theta$ neither goes beyond nor below the slowest and quickest responses. Also, we simply assume that the ratio between each two $\Theta_{i}$ is a space-time constant:

$\alpha_{i}=\frac{\Theta_{i}}{\Theta_{1}}$.

This is consistent with the CREST model, as shown in Eq. (4). Based on Eq. (19), $\alpha_{1}$ is always 1 and $\alpha_{2}$ is the $\alpha$ parameter of Eq. (4). From Eqs. (18) and (19), we may further write

$\Theta=\xi_{i} \Theta_{i}$,

where

$\xi_{i}=\frac{1}{\alpha_{i}} \sum_{i}^{N} \psi_{i} \alpha_{i}$

$\xi_{i}$ is the ratio between the weighted average of $\alpha_{i}$ (with respect to $\psi_{i}$ ) and $\alpha_{i}$. It is a measure of disparity in routing time from a rainfall excess component to the total one. It accounts for the hydrologic and geomorphologic effects as the inclusion of $\psi_{i}$ and $\alpha_{i}$. With Eq. (20), the expectation of $T_{\mathrm{n}}$ is derived as (see Appendix C)

$E\left(T_{\mathrm{n}}\right)=\sum_{i}^{N} \psi_{i} \xi_{i} E_{i}\left(T_{\mathrm{n}, i}\right)$.

Mathematically, Eq. (22) indicates that $E\left(T_{\mathrm{n}}\right)$ is the expectation of $\xi_{i} E_{i}\left(T_{\mathrm{n}, i}\right)$, but not $E_{i}\left(T_{\mathrm{n}, i}\right)$, with respect to $\psi_{i}$. Equation (22) implies that both the hydrologic and geomorphologic effects are accounted for by combining all the $E_{i}\left(T_{\mathrm{n}, i}\right)$ components in $E\left(T_{\mathrm{n}}\right)$. Substituting Eqs. (12) and (17) into Eq. (22), $E\left(T_{\mathrm{n}}\right)$ can be written as

$E\left(T_{\mathrm{n}}\right)=\underbrace{\xi_{i}\left[\Theta_{i}\right]_{\mathrm{a}}}_{E_{3}}+\underbrace{\frac{\xi_{i}\left\{\Theta_{i}, \sum_{i}^{N}\left[R_{i}\right]_{\mathrm{t}}\right\}_{\mathrm{a}}}{[R]_{\mathrm{at}}}}_{E_{4}}$. 
$E_{3}$ stands for the spatial mean of runoff routing time in the hillslope and channel network. $E_{4}$ is the expected distance from the geomorphologic center of catchment to the centroid of storm-average rainfall excess.

The right panel of Fig. 8 shows the magnitude of terms from Eq. (23) for all events with the mean magnitude reported in the middle three rows of Table 2. As expected, $E\left(T_{\mathrm{n}}\right)$ increases according to catchment drainage area, which is mainly attributed to the elongation in flow path (i.e., increases in $\left.E_{3}\right)$. The spatial covariance term $\left(E_{4}\right)$ is low, indicating that the contours of rainfall excess are not followed by the contours of isochrones for runoff routing (Woods and Sivapalan, 1999; Sangati et al., 2009; Viglione et al., 2010b; Volpi et al., 2012). This is anticipated given the low elevation and mild slope topographic setups of the study region causing no orographic pattern in rainfall excess. Componentwise, the subsurface routing takes longer than the surface one as shown in Fig. 3. Under the relationship specified by Eq. (22), values of the total $E\left(T_{\mathrm{n}}\right)$ are in between the subsurface and surface $E\left(T_{\mathrm{n}}\right)$. We also observe from the figure that $E\left(T_{\mathrm{n}}\right)$ values of the two components are getting closer to the total $E\left(T_{\mathrm{n}}\right)$ with the increase of the drainage area. This reflects the trend of change in mean $\xi$ where mean $\xi$ values for the two components are getting closer from Swift to Tar given that the two $\psi$ values remain relatively unchanged. The June 2006 event is an example showing that the subsurface process is characterized by negative spatial covariance ( $E_{4}$ is about $-4 \mathrm{~h}$ for all catchments). This is explained by its outlet-concentrated cumulative rainfall (Fig. 2). Moreover, comparing $E\left(T_{\mathrm{r}}\right), E\left(T_{\mathrm{n}}\right)$, and $E\left(T_{q}\right)$ in Table 2, we note that the delay in catchment response is increasing with drainage area; contributions to $E\left(T_{q}\right)$ from the two stages are comparable in magnitude, with $E\left(T_{\mathrm{r}}\right)$ being mostly larger than $E\left(T_{q}\right)$.

\subsubsection{Variance of catchment response time}

In the two-stage analytical framework, the variance of catchment response time is contributed by the variances introduced from the holding time of each of the stages and the covariance between the holding time of the two stages. We write that

$$
\operatorname{var}\left(T_{q}\right)=\underbrace{\operatorname{var}\left(T_{\mathrm{r}}\right)}_{\text {Stage1 }}+\underbrace{\operatorname{var}\left(T_{\mathrm{n}}\right)}_{\text {Stage2 }}+\underbrace{2 \operatorname{cov}\left(T_{\mathrm{r}}, T_{\mathrm{n}}\right)}_{\text {Movement }} .
$$

For stage 1, the variance of delay in rainfall excess generation for a rainfall excess component is provided as (see Appendix D)

$$
\begin{aligned}
\operatorname{var}_{i}\left(T_{\mathrm{r}, i}\right)=\frac{\left|T_{\mathrm{P}}\right|^{2}}{12} \\
+\frac{\left\{T^{2},\left[R_{i}\right]_{\mathrm{a}}\right\}_{\mathrm{t}}-\left|T_{\mathrm{P}}\right|\left\{T,\left[R_{i}\right]_{\mathrm{a}}\right\}_{\mathrm{t}}-\frac{\left(\left\{T,\left[R_{i}\right]_{\mathrm{a}}\right\}_{\mathrm{t}}\right)^{2}}{\left[R_{i}\right]_{\mathrm{at}}}}{\left[R_{i}\right]_{\mathrm{at}}} .
\end{aligned}
$$

Here, $\operatorname{var}_{i}\left(T_{\mathrm{r}, i}\right)$ represents the variance of instantaneous time with respect to the temporal distribution of rainfall excess; the second term is null for temporal uniform rainfall excess or rainfall excess concentrated purely on the event midpoint.

For total rainfall excess, the variance of delay in rainfall excess generation, $\operatorname{var}\left(T_{\mathrm{r}}\right)$, is correlated with $\operatorname{var}_{i}\left(T_{\mathrm{r}, i}\right)$ as (see Appendix D for derivations)

$\operatorname{var}\left(T_{\mathrm{r}}\right)=\sum_{i}^{N} \psi_{i} \operatorname{var}_{i}\left(T_{\mathrm{r}, i}\right)+\sum_{i}^{N} \psi_{i}\left[E_{i}\left(T_{\mathrm{r}, i}\right)-E\left(T_{\mathrm{r}}\right)\right]^{2}$.

The first term is clearly the expectation of variance from all the other components. It signifies that the larger the rainfall excess component, the stronger the control in dispersion of the total rainfall excess. The second term is the variability of $E_{i}\left(T_{\mathrm{r}, i}\right)$ that arises since variance is not a linear operator. It measures the mean difference in the temporal mass center between each of the components to the total rainfall excess. The first and the second term account for the intra- and inter-component variability. Substituting in Eqs. (14), (16), and (25) to Eq. (26), a complete form is given as

$$
\begin{aligned}
\operatorname{var}\left(T_{\mathrm{r}}\right)=\underbrace{\frac{\left[T_{\mathrm{P}}\right]^{2}}{12}}_{v_{1}} & \\
+ & \underbrace{\frac{\left\{T^{2}, \sum_{i}^{N}\left[R_{i}\right]_{\mathrm{a}}\right\}_{\mathrm{t}}-\left|T_{\mathrm{P}}\right|\left\{T, \sum_{i}^{N}\left[R_{i}\right]_{\mathrm{a}}\right\}_{\mathrm{t}}-\frac{\sum_{i}^{N}\left(\left\{T,\left[R_{i}\right]_{\mathrm{a}}\right\}_{\mathrm{t}}\right)^{2}}{\left[R R_{i}\right]_{\mathrm{at}}}}{[R]_{\mathrm{at}}}}_{v_{2}} \\
+ & \underbrace{\sum_{i}^{N} \psi_{i}\left(\frac{\left\{T,\left[R_{i}\right]_{\mathrm{a}}\right\}_{\mathrm{t}}}{\left[R_{i}\right]_{\mathrm{at}}}-\frac{\left\{T, \sum_{i}^{N}\left[R_{i}\right]_{\mathrm{a}}\right\}}{[R]_{\mathrm{at}}}\right)^{2}}_{L_{\mathrm{r}}} .
\end{aligned}
$$

Term $v_{1}$ stands for the variance in time generated by a temporal invariant catchment-average rainfall excess. Term $v_{2}$ represents component-wise mean of additional variance caused by the temporal variation in catchment-average rainfall excess. The last term is named $L_{\mathrm{r}}$ and represents the mean square of "time lag" (between each component to the total) in rainfall excess generation.

Results for Eq. (27) are illustrated in the left panel of Fig. 9 and the first four rows of Table 3. The major source of $\operatorname{var}\left(T_{\mathrm{r}}\right)$ is the variance of event duration $\left(v_{1}\right)$. However, the additional variance caused by the temporal interaction between rainfall excess and time $\left(v_{2}\right)$ is not negligible. This states that the distributions of rainfall excess of the events are not uniform in time (Woods and Sivapalan, 1999; Viglione et al., 2010b). Additionally, event time series of the two rainfall excess components are equally dispersed during the event period given the fairly close $\operatorname{var}\left(T_{\mathrm{r}}\right)$ values (only the Swift 
Table 3. The same as Table 1 but for Eqs. (27), (30), and (33).

\begin{tabular}{|c|c|c|c|c|c|c|c|c|c|}
\hline \multirow[t]{2}{*}{ Term } & \multicolumn{3}{|c|}{ Swift } & \multicolumn{3}{|c|}{ Fishing } & \multicolumn{3}{|c|}{ Tar } \\
\hline & Subsurface & Surface & Total & Subsurface & Surface & Total & Subsurface & Surface & Total \\
\hline$v_{1}$ & 536 & 536 & 536 & 769 & 769 & 769 & 740 & 740 & 740 \\
\hline$v_{2}$ & 73 & 103 & 86 & 19 & 22 & 21 & 60 & 60 & 61 \\
\hline$L_{\mathrm{r}}$ & - & - & 7.6 & - & - & 2.4 & - & - & 2.5 \\
\hline $\operatorname{var}\left(T_{\mathrm{r}}\right)$ & 609 & 638 & 629 & 788 & 791 & 792 & 800 & 800 & 803 \\
\hline$v_{3}$ & 223 & 21 & 112 & 150 & 59 & 106 & 340 & 152 & 244 \\
\hline$v_{4}$ & -22 & -1.0 & -8.8 & -7.7 & -2.6 & -5.1 & -10 & -3.4 & -6.7 \\
\hline$L_{\mathrm{n}}$ & - & - & 0.65 & - & - & 0.18 & - & - & 0.58 \\
\hline $\operatorname{var}\left(T_{\mathrm{n}}\right)$ & 201 & 20 & 103 & 142 & 56 & 101 & 330 & 149 & 238 \\
\hline c & 3.3 & -1.1 & -1.2 & -26 & -16 & -22 & -28 & -19 & -23 \\
\hline$L_{\mathrm{r}, \mathrm{n}}$ & - & - & -0.59 & - & - & -0.56 & - & - & -0.82 \\
\hline $\operatorname{cov}\left(T_{\mathrm{r}}, T_{\mathrm{n}}\right)$ & 3.3 & -1.1 & -1.8 & -26 & -16 & -23 & -28 & -19 & -24 \\
\hline $\operatorname{var}\left(T_{q}\right)$ & 813 & 658 & 730 & 904 & 831 & 871 & 1102 & 930 & 1017 \\
\hline
\end{tabular}
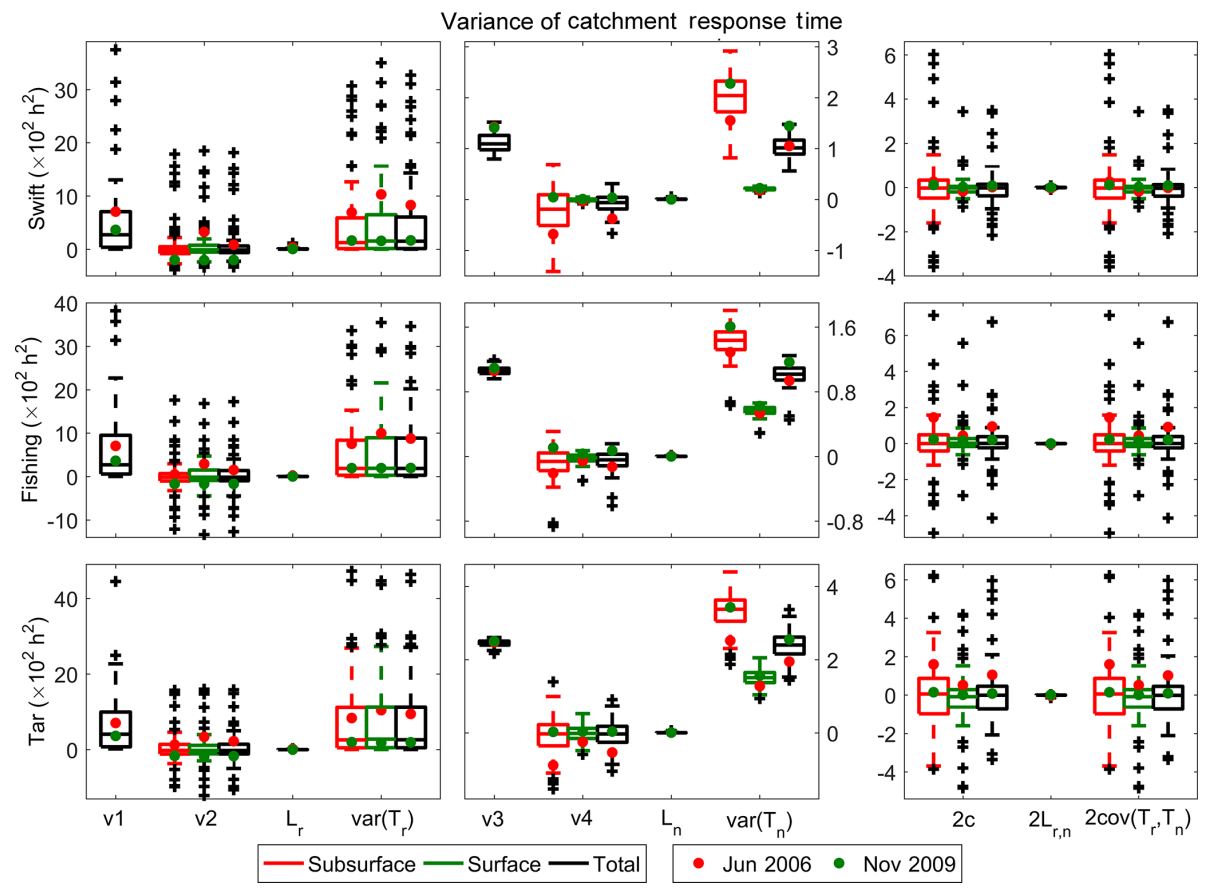

Figure 9. The same as Fig. 7 but for Eqs. (27), (30), and (33).

case shows medium difference). This is exemplified by Fig. 4 where the shapes of time series for the two components are quite close in the Fishing and Tar cases but a bit more deviated in the Swift. Besides, by comparing the time series of the two test events we can see that the June 2006 event is characterized by multiple peak rainfall values, while the November 2009 is closer to a single-peak event. These general differences in shapes are well described by the positive and negative signs of term $v_{2}$ for the first and second events. Results from the figure and table also suggest that the magnitude of the time lag term $\left(L_{\mathrm{r}}\right)$ is irrelevant. A better visualization of reason is provided by the sample events' time series in Fig. 4 .
Most of the temporal variability of rainfall is preserved in the time series as we can see from the shapes of $[P]_{\mathrm{a}}\left[W_{1}\right]_{\mathrm{a}}$ and $[P]_{\mathrm{a}}\left[W_{2}\right]_{\mathrm{a}}$. Inspection of $\operatorname{var}\left(T_{\mathrm{r}}\right)$ reveals that although the magnitudes of $v_{1}, v_{2}$, and $L_{\mathrm{r}}$ show no scale dependency, their combination, $\operatorname{var}\left(T_{\mathrm{r}}\right)$, is increasing with drainage area.

For the runoff routing stage, we derive the variance of runoff routing time for any rainfall excess component, $\operatorname{var}_{i}\left(T_{\mathrm{n}, i}\right)$, as (refer to Appendix E)

$$
\begin{aligned}
& \operatorname{var}_{i}\left(T_{\mathrm{n}, i}\right)=\left\{\Theta_{i}\right\}_{\mathrm{a}} \\
& +\frac{\left\{\Theta_{i}^{2},\left[R_{i}\right]_{\mathrm{t}}\right\}_{\mathrm{a}}-2\left[\Theta_{i}\right]_{\mathrm{a}}\left\{\Theta_{i},\left[R_{i}\right]_{\mathrm{t}}\right\}_{\mathrm{a}}-\frac{\left(\left\{\Theta_{i},\left[R_{i}\right]_{\mathrm{t}}\right\}_{\mathrm{a}}\right)^{2}}{\left[R_{i}\right]_{\mathrm{at}}}}{\left[R_{i}\right]_{\mathrm{at}}} .
\end{aligned}
$$


The first term is the spatial variance of the runoff routing time. The second one accounts for the additional variance introduced by the interaction between time-average rainfall excess and the runoff routing time. If the rainfall excess is spatially uniform or concentrated on the isochrones representing the mean runoff routing time (i.e., $[\Theta]_{\mathrm{a}}$ ), the second term vanishes.

We may derive the variance of delay in runoff routing, $\operatorname{var}\left(T_{\mathrm{n}}\right)$, as (see Appendix E)

$$
\begin{aligned}
\operatorname{var}\left(T_{\mathrm{n}}\right) & =\sum_{i}^{N} \psi_{i} \xi_{i}^{2} \operatorname{var}_{i}\left(T_{\mathrm{n}, i}\right) \\
& +\sum_{i}^{N} \psi_{i}\left[\xi_{i} E_{i}\left(T_{\mathrm{n}, i}\right)-E\left(T_{\mathrm{n}}\right)\right]^{2}
\end{aligned}
$$

Similarly, $\operatorname{var}\left(T_{\mathrm{n}}\right)$ has two terms accounting for the intraand inter-component variability of runoff routing. The first term is a linear combination of $\xi_{i}^{2} \operatorname{var}_{i}\left(T_{\mathrm{n}, i}\right)$; it highlights the combined effect from hydrology and geomorphology in the intra-component variability. The second term is the variance of $\xi_{i} E_{i}\left(T_{\mathrm{n}, i}\right)$; it quantifies the squared mean distance in spatial mass center between all components to the total. Hence, $\operatorname{var}\left(T_{\mathrm{n}}\right)$ may be rewritten as

$$
\begin{aligned}
& \operatorname{var}\left(T_{\mathrm{n}}\right)=\underbrace{\xi_{i}^{2}\left\{\Theta_{i}\right\}_{\mathrm{a}}}_{v_{3}} \\
& +\underbrace{\xi_{i}^{2}\left\{\Theta_{i}^{2}, \sum_{i}^{N}\left[R_{i}\right]_{\mathrm{t}}\right\}_{\mathrm{a}}-2 \xi_{i}^{2}\left[\Theta_{i}\right]_{\mathrm{a}}\left\{\Theta_{i}, \sum_{i}^{n}\left[R_{i}\right]_{\mathrm{t}}\right\}-\frac{\sum_{i}^{N} \xi_{i}^{2}\left(\left\{\Theta_{i},\left[R_{i}\right]_{\mathrm{t}}\right\}\right)^{2}}{\left[R_{i}\right]_{\mathrm{at}}}}_{v_{4}} \\
& +\underbrace{\sum_{i}^{N} \psi_{i} \xi_{i}^{2}\left(\frac{\left\{\Theta_{i},\left[R_{i}\right]_{\mathrm{t}}\right\}_{\mathrm{a}}}{\left[R_{i}\right]_{\mathrm{at}}}-\frac{\left\{\Theta_{i}, \sum_{i}^{N}\left[R_{i}\right]_{\mathrm{t}}\right\}}{[R]_{\mathrm{at}}}\right)^{2}}_{L_{\mathrm{n}}}
\end{aligned}
$$

Term $v_{3}$ represents the variance in time generated by a spatial invariant storm-average rainfall excess. Term $v_{4}$ is the mean of additional variance caused by the spatial variation in storm-average rainfall excess. The term $L_{\mathrm{n}}$ represents the mean of time lag in runoff routing between rainfall excess components to the total.

The magnitudes of terms in Eq. (30) are plotted in the middle panel of Fig. 9 with mean statistics listed in Table 3 (the middle four rows). Results suggest that $v_{3}$ is the main contributor of $\operatorname{var}\left(T_{\mathrm{n}}\right)$ compared to the additional spatial variance $\left(v_{4}\right), v_{4}$ is positively skewed as shown in the figure with negative mean, indicating that the event rainfall excess tends to be concentrated by the catchment (i.e., spatially unimodal pattern) (Zoccatelli et al., 2011; Mei et al., 2014). $v_{4}$ is low in magnitude because, again, there is little spatial correlation between the location of isochrones for runoff routing and the rainfall excess under the study area's topographic setups. Component-wise comparison reveals that the variance of delay in runoff routing of the surface rainfall excess is smaller than the subsurface one. This is ascribed to the larger magnitude of $\Theta_{1}$ and $\left[R_{1}\right]_{\text {at }}$ than $\Theta_{2}$ and $\left[R_{2}\right]_{\mathrm{at}}$. Besides, results suggest a negligible time lag term $\left(L_{\mathrm{n}}\right)$ in contribution to the total variance of runoff routing, meaning that the spatial mass center of rainfall excess for the two rainfall excess components is fairly close to the total one. This is an expected result because of the highly similar spatial pattern of rainfall excess and runoff routing for the two components. Observations of the two sample events demonstrate that $v_{4}$ for the November 2009 event is closer to null (for instance, $v_{4}$ of the Tar catchment is $4 \mathrm{~h}^{2}$ compared to $50 \mathrm{~h}^{2}$ of the June 2006 event). This is substantiated by the generally more uniformly distributed rainfall excess pattern of the November event $\left([R]_{\mathrm{t}}\right.$ in Fig. 5). Moreover, we compare the values of $\operatorname{var}\left(T_{\mathrm{n}}\right)$ and $\operatorname{var}\left(T_{\mathrm{r}}\right)$ from the results. Obviously, $\operatorname{var}\left(T_{\mathrm{r}}\right)$ dominates $\operatorname{var}\left(T_{q}\right)$ where the mean of $\operatorname{var}\left(T_{\mathrm{r}}\right)$ is at least more than 3 times the mean of $\operatorname{var}\left(T_{\mathrm{n}}\right)$.

The covariance term in Eq. (17) is often interpreted as an indicator of "movement of storm", resulting from the relaxation of the "stationary rainfall" assumption. The so-called movement of storm is not just the geographic movement; it also accounts for the change in the space-time dynamic of rainfall excess with respect to the runoff routing during the storm period (Viglione et al., 2010a; Zoccatelli et al., 2011; Nikolopoulos et al., 2014; Mei et al., 2014). The form of $\operatorname{cov}_{i}\left(T_{\mathrm{r}}, T_{\mathrm{n}}\right)$ is written as (refer to Appendix F for details)

$$
\begin{gathered}
\operatorname{cov}_{i}\left(T_{\mathrm{r}, i}, T_{\mathrm{n}, i}\right)=\frac{\left\{T,\left\{\Theta_{i}, R_{i}\right\}_{\mathrm{a}}\right\}_{\mathrm{t}}}{\left[R_{i}\right]_{\mathrm{at}}} \\
-\frac{\left\{T,\left[R_{i}\right]_{\mathrm{a}}\right\}_{\mathrm{t}}\left\{\Theta_{i},\left[R_{i}\right]_{\mathrm{t}}\right\}_{\mathrm{a}}}{\left[R_{i}\right]_{\mathrm{at}}^{2}} .
\end{gathered}
$$

This term is the additional variance generated from the correlation in runoff generation and routing. Positive and negative covariance are interpreted as the centroid of rainfall excess moving towards the catchment portion with longer or shorter runoff routing time (near periphery or outlet) as the event evolves.

The covariance term in our multicomponent assumption may be written as (see Appendix F)

$$
\begin{aligned}
& \operatorname{cov}\left(T_{\mathrm{r}}, T_{\mathrm{n}}\right)=\sum_{i}^{N} \psi_{i} \xi_{i} \operatorname{cov}_{i}\left(T_{\mathrm{r}, i}, T_{\mathrm{n}, i}\right) \\
& +\sum_{i}^{N} \psi_{i}\left[E_{i}\left(T_{\mathrm{r}, i}\right) \xi_{i} E_{i}\left(T_{\mathrm{n}, i}\right)-E\left(T_{\mathrm{r}}\right) E\left(T_{\mathrm{n}}\right)\right] .
\end{aligned}
$$

The covariance operator also results in two terms where the first one is the component-wise expectation of covariance between $T_{\mathrm{r}, i}$ and $\xi_{i} T_{\mathrm{n}, i}$ with respect to $\psi_{i}$; it measures the coevolution of all rainfall excess components over catchment and event period. The second term is the covariance between $E_{i}\left(T_{\mathrm{r}, i}\right)$ and $\xi_{i} E_{i}\left(T_{\mathrm{n}, i}\right)$; a positive or negative value of the 
second term implies that rainfall excess components with temporal mass centers' distance from the early phase of event are located closer to the catchment portion with larger or smaller routing time (catchment periphery or outlet). Based on this interpretation, the inter-component covariance should be very small in most of the cases happening in nature; this is because there is no restriction that a rainfall excess component with a time center further away from the event midpoint should be centered over isochrones with longer routing time or vice versa. $\xi_{i}$ is not subjected to the covariance operator and can be moved out. Combining Eqs. (31) and (32), $\operatorname{cov}\left(T_{\mathrm{r}}\right.$, $T_{\mathrm{n}}$ ) may be further written as

$$
\begin{aligned}
& \operatorname{cov}\left(T_{\mathrm{r}}, T_{\mathrm{n}}\right)=\underbrace{\underbrace{N}_{i} \xi_{i}\left(\left\{T,\left\{\Theta_{i}, R_{i}\right\}_{\mathrm{a}}\right\}_{\mathrm{t}}-\frac{\left\{T,\left[R_{i}\right]_{\mathrm{a}}\right\}_{\mathrm{t}}\left\{\Theta_{i},\left[R_{i}\right]_{\mathrm{t}}\right\}_{\mathrm{a}}}{\left[R_{i}\right]_{\mathrm{at}}}\right)}_{c} \\
& +\underbrace{[R]_{\mathrm{at}}}_{L_{\mathrm{r}, \mathrm{n}}}
\end{aligned}
$$

Magnitudes of terms in Eq. (33) for the surface and subsurface components and the total are rendered in the right panel of Fig. 9 with mean of terms reported in Table 3. Note that the magnitudes of terms have been multiplied by 2 given the mass conservation in Eq. (24). Values of the covariance terms are almost symmetrically distributed at 0 and slightly positively skewed. This observation indicates that there is no clear tendency for the storm movement. This is again explained by the fact that there is no preferred spatial pattern of rainfall over the study region with negligible orographic enhancement. The $L_{\mathrm{r}, \mathrm{n}}$ term reveals an insignificant effect from the inter-component covariance between the temporal and spatial mass center of rainfall excess. This result supports our first guess on the magnitude of $L_{\mathrm{r}, \mathrm{n}}$. Due to the low $L_{\mathrm{r}, \mathrm{n}}$, $\operatorname{cov}\left(T_{\mathrm{r}}, T_{\mathrm{n}}\right)$ is mainly manipulated by $c$. Inspection of magnitudes of the two rainfall excess components demonstrates that the correlation between $T_{\mathrm{r}}$ and $T_{\mathrm{n}}$ for the subsurface one is higher. Meanwhile, we observe an increase of $\operatorname{cov}\left(T_{\mathrm{r}}, T_{\mathrm{n}}\right)$ magnitude from the Swift to the Tar catchment, consisting of the positive scale dependency in magnitude of storm movement concluded in Mei et al. (2014) over the same area. In all, the movement effect of rainfall excess in variance of catchment response is relatively insignificant in the study region.

\section{Role of the analytical framework on flood characteristics}

The rainfall and catchment surface properties are intimately related with the generation of the flood. Specifically, the analytical framework quantities, $[R]_{\mathrm{at}}, E\left(T_{q}\right)$, and $\operatorname{var}\left(T_{q}\right)$, are correlated with the cumulative volume $(V)$, centroid $(C)$, and spreadness $(S)$ of event flow time series, respectively (Sangati et al., 2009; Viglione et al., 2010a, b; Mejía and Moglen,
2010; Volpi et al., 2012). To address the question of how sensitive the framework quantities are to the flood characteristics, we conducted sensitivity tests with respect to the flow simulations and observations in this section. The $V, C$, and $S$, which quantify the catchment flood response, are defined as

$$
\begin{aligned}
& V=\int_{T_{\mathrm{F}}} Q(t) \mathrm{d} t \\
& C=\frac{\int_{T_{\mathrm{F}}} t \cdot Q(t) \mathrm{d} t}{\int_{T_{\mathrm{F}}} Q(t) \mathrm{d} t} \\
& S=\sqrt{\frac{\int_{T_{\mathrm{F}}}(t-C)^{2} Q(t) \mathrm{d} t}{\int_{T_{\mathrm{F}}} Q(t) \mathrm{d} t}},
\end{aligned}
$$

where $Q(t)$ is either the simulated or observed event flow time series; $T_{\mathrm{F}}$ corresponds to the flood event period. $V$ reflects the magnitude of cumulative flow of a flood event while $C$ and $S$ are related to the shape of the flood event hydrograph. Specifically, $C$ is the temporal location of mass center of the hydrograph which can be used to surrogate the time to peak (for single-peak hydrographs); $S$ represents the temporal degree of dispersion with respect to $C$; typically, for a unimodal event, the larger $S$ indicates a less-concentrated peak for the hydrograph.

Results of the sensitivity tests with respect to simulations and observations are illustrated in Figure 10 and Table 4. Overall, the catchment-average cumulative rainfall excess $\left([R]_{\mathrm{at}}\left|T_{\mathrm{P}}\right|\right)$ shows relatively high consistency with the cumulative flow volume derived by the model simulations (upper left panel), especially for the Fishing and Tar catchments where the means of mean error (ME) are within $1 \mathrm{~mm}$ for the events. For the Swift cases, a fairly slight overestimation of $V$ by merely $3 \mathrm{~mm}$ (in terms of mean ME) is observed. Table 4 also provides the CRMS as an indicator of the random error in estimating $V$. Magnitudes of CRMS are fairly small at around $1.5 \mathrm{~mm}$, considering that these are produced based on cumulative volume. A comparison between ME and CRMS gives more insights on the performance of the analytical framework. Random error is the main error source for the Fishing and Tar cases, while in the Swift systematic overestimation is more dominated. On the other hand, comparisons between the framework $[R]_{\text {at }}\left|T_{\mathrm{P}}\right|$ and $V$ derived from the observed flow show significant reduction in linearity of the relationship (upper right panel of Fig. 10). This is also reflected by the higher CRMS values in Table 4 (CRMS of $V$ compared to the observations are at least $3 \mathrm{~mm}$ larger than those compared with the model simulations). ME values, with respect to the observed $V$ for the Fishing and Tar catchments, are still relatively low (lower than the CRMS of $V$ ) while the Swift case is characterized by $5.4 \mathrm{~mm}$ of ME. In all, the analytical framework provides reliable estimation on the cumu- 
Table 4. Statistics of the sensitivity tests.

\begin{tabular}{|c|c|c|c|c|c|c|c|}
\hline \multirow{2}{*}{$\begin{array}{l}\text { Reference } \\
\text { type }\end{array}$} & \multirow[t]{2}{*}{ Basin } & \multicolumn{3}{|c|}{ Mean error } & \multicolumn{3}{|c|}{ Centered root mean square } \\
\hline & & $V(\mathrm{~mm})$ & $C(\mathrm{~h})$ & $S(\mathrm{~h})$ & $V(\mathrm{~mm})$ & $C(\mathrm{~h})$ & $S(\mathrm{~h})$ \\
\hline \multirow{3}{*}{$\begin{array}{l}\text { Model } \\
\text { simulation }\end{array}$} & Swift & 2.9 & -35.2 & -12.7 & 1.6 & 7.6 & 5.7 \\
\hline & Fishing & -0.6 & -36.9 & -10.7 & 1.6 & 3.8 & 5.5 \\
\hline & Tar & 0.6 & -39.6 & -15.2 & 1.3 & 6.5 & 5.4 \\
\hline \multirow[t]{3}{*}{ Observation } & Swift & 5.4 & -26.8 & -10.2 & 6.2 & 13.4 & 9.2 \\
\hline & Fishing & 1.5 & -30.9 & -8.2 & 4.8 & 10.5 & 8.7 \\
\hline & Tar & 1.7 & -34.1 & -7.6 & 5.7 & 12.5 & 7.6 \\
\hline
\end{tabular}
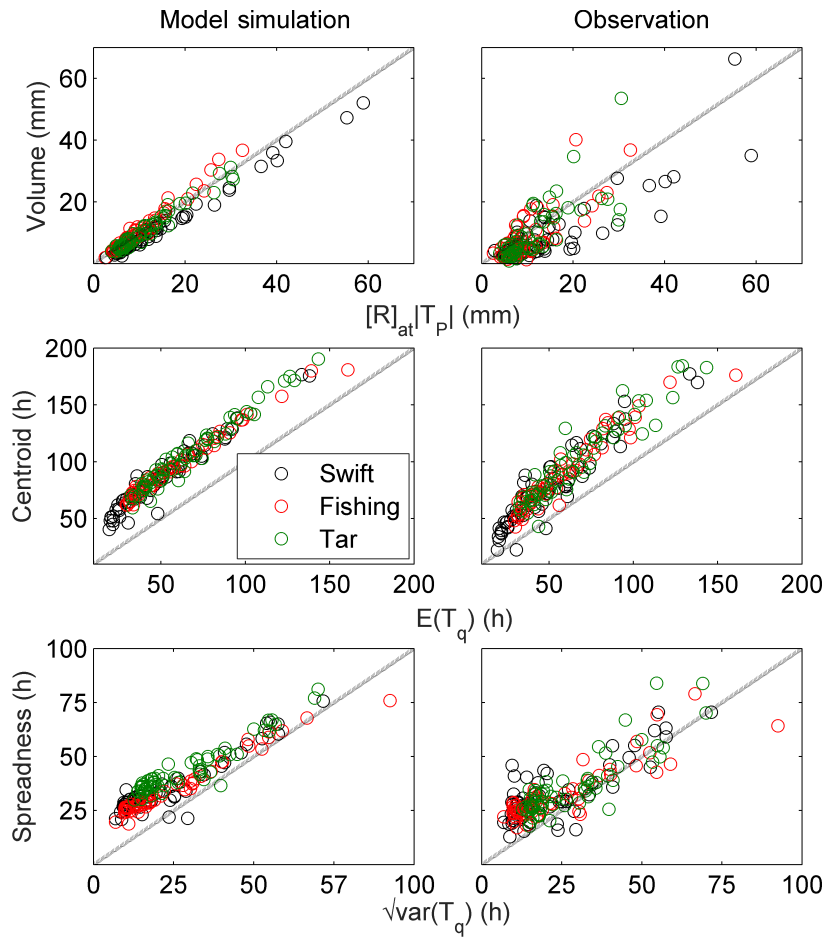

Figure 10. Scatterplots of the analytical framework outputs vs. hydrograph properties.

lative volume, especially when compared to the model simulations, given the low magnitudes of ME and CRMS. The sensitivity of framework-predicted cumulative volume shows noticeable drop from comparing the model simulations to the observed flow.

The middle panel of Fig. 10 demonstrates the correlation between the expectation of catchment response time and centroid of the flood event. Both of the sensitivity tests against the flow simulations and observations show that $E\left(T_{q}\right)$ values are positively correlated with $C$ but with apparent underestimations. For the simulation-based sensitivity test, the systematic underestimation on event centroid is about $35 \mathrm{~h}$ for events from the smallest basin and increases to $40 \mathrm{~h}$ for events from the largest basin. The random components of error are within $20 \%$ of the systematic one in magnitude. Results of the observation-based sensitivity test indicate lower systematic error by the analytical framework but, as expected, a higher degree of random error (ME values are about $80 \%$ of the simulated-based tests but CRMS are twice as those). This signifies that the main issue in estimation of $C$ is the systematic underestimation from the analytical framework. This underestimation lies in the simplified structure of the analytical framework compared to a distributed hydrologic model in both land surface and routing processes. In the land surface process, during the early phase of the event, precipitation is principally used to fill the water capacity of catchment under the infiltration excess; after a certain time period, flow rate rises rapidly with the existence of precipitation because of the saturation excess process. This can be visualized by the sample events' time series in Fig. 2. Consequently, the inclusion of precipitation before the functioning of saturation excess advances the temporal mass center of rainfall, leading to underestimation of the mass center location. Furthermore, in the analytical framework, a water parcel is approximated traveling at a constant speed once it enters the basin while the linear reservoir routing scheme of CREST only discharges a portion of the water amount from the total storage in a given grid cell, which in turn increases the equivalent traveling time. Given that the hydrologic simulations provide reasonable performance with respect to the observed flow, systematic underestimation by $E\left(T_{q}\right)$ to the observation-derived $C$ is also seen.

The spreadness is compared to the standard deviation of the catchment response time (square root of variance of the catchment response time) in the last panel of Fig. 10. Systematic underestimation is still the major source of error in the estimation for the simulation-based tests. Its magnitudes are about $-12 \mathrm{~h}$ and the magnitudes decrease with increasing spreadness. ME values of the observed-based sensitivity tests also reveal systematic underestimation but to lesser significance against the simulation-based ones. The random error reaches similar magnitudes of systematic error (about $9 \mathrm{~h}$ ) due to the increase in nonlinearity of the $\sqrt{\operatorname{var}\left(T_{q}\right)}$-to- $S$ relationship. The underestimation in $S$ also originates from the differences in structure of a distributed hydrologic model 
and the framework. During the early phase of event, the infiltration excess is the dominant mechanism for runoff generation. Under such a condition, the flow rate rises gradually and the hydrograph tends to be smooth, implying high spreadness. One can take the November 2009 event as an example; instead of having one rapid rising, the Swift catchment hydrograph has two rising limbs due to the switch in the rainfall excess generation mechanism. This bi-modal shape introduces larger spreadness compared to a unimodal rising shape. A similar argument regarding the influence of infiltration excess on runoff generation has been reviewed in Mei et al. (2014). Their study argues that the low sensitivity between shape error of rainfall and simulated runoff shown for the events is because most of the events from the Tar region do not have a bank-full condition. On the other hand, the equivalent travel time in the runoff routing is underestimated, and this underestimation is increasing with the length of the water path, given that $\Theta$ represents a cumulative sum along the water path (Eq. 3). This leads to underestimation in the variability of traveling time by the framework. To sum up, the analytical framework works better in predicting the spreadness of hydrograph compared to the centroid. Mean values of ME for $S$ are approximately $38 \%$ of the $C$ case for the comparisons with simulated and observed flow, respectively.

\section{Conclusions}

We presented an expansion of V2010 hydrologic analytical framework under the consideration of multiple components in catchment flood response. To demonstrate the framework in this study we fixed the number of flow generation components to two (surface and subsurface), and used a distributed hydrological model (CREST) to provide the necessary framework parameters and event flow hydrographs. We demonstrated the framework based on a large number of flood events that occurred between 2003 and 2012 over three subcatchments of the Tar River basin. Two of the flood events were used for a detailed demonstration of the framework. Sensitivity tests were rendered to investigate the correlation between framework and flood characteristics. The findings from this study are summarized below.

For the aspect of rainfall excess generation, we showed that the amount of rainfall excess generation is inversely proportional to catchment size. The most significant contribution came from the product term between space-time aggregated rainfall and runoff coefficients, while spatial and temporal correlation and movement effects were not significant. In addition, it was shown that the subsurface component outperformed the surface component of runoff in the contribution to rainfall excess generation, but this difference diminished in larger catchments.

The expectation of catchment response time was also investigated. We found that the total rainfall excess generation time is a linear combination of the expected generation times of all rainfall excess components weighted by their rainfall excess ratio. The total runoff routing time is also a combination of routing times of all rainfall excess components weighted according to their rainfall excess ratio. Results show that both rainfall excess generation and runoff routing stages are important to the timing of the catchment response. The length of the rainfall event and the magnitude of the runoff routing time play a significant role in controlling the timing of the hydrograph. Delay in response due to the spatial and temporal correlation term is low. The total catchment response time was shown to be closer to the subsurface rainfall excess one, indicating a higher degree of influence, which agrees with the higher rainfall excess ratio for the subsurface component. However, the value gap between components narrows from small to large catchment areas.

For the variance of catchment response time, our findings showed that the total variance in rainfall excess generation comes from two parts - the linear combination of all components' variance and the variance of expected rainfall excess generation time for components. These two parts account for the intra- and inter-component variability, respectively. The total variance in delay due to the runoff routing stage consists of two parts - a combination of variances from all the other components and the variance of expected runoff routing time with the participation of the hydrologic and geomorphologic related coefficients. Analogously, the covariance between holding time of the two stages also consists of two parts - the expectation of component covariance and the covariance between expectations of rainfall excess generation and runoff routing. Results revealed that variance of the rainfall excess generation stage is of higher importance than that of the runoff routing stage. For stage 1, the variance from rainfall duration was more important than the additional variance from temporal interactions between rainfall excess and time. For stage 2, the spatial variance of runoff routing time outperformed the additional variance that rose from the spatial interaction between rainfall excess and runoff routing. Additionally, variance of the surface component was closer to the total variance, indicating a higher degree of influence. Furthermore, the inter-component variability was negligible compared to the intra-component variability.

Results from the sensitivity analysis revealed that the framework is characterized by relatively low random errors in estimating the flood characteristics. The random errors were larger in the observation-based sensitivity tests compared to the simulation-based ones. A slight overestimation was found in the Swift catchment on the estimation of cumulative flow volume. Systematic underestimation in event centroid and spreadness were notable, especially for the timing issue, which demonstrates an increasing trend with catchment scale. Moreover, for the simulation-based sensitivity tests, the underestimation of spreadness was reduced with the increase in magnitude of spreadness.

From the herein analytical framework results, we showed that magnitudes of the new time lag terms are low. We be- 
lieve this is not a general finding because the surface runoff coefficient was represented by a constant imperviousness ratio $\left(I_{\mathrm{M}}\right)$ for this study and the runoff routing times for the two components had the same spatial pattern (differed merely in magnitude by the constant $\alpha$ ). Future studies will need to replace the constant imperviousness ratio by a spatially distributed variable to mimic the spatial variability of the very fast flood response of a catchment. Also, we suggest using spatially varied $\alpha_{i}$ to better represent the differences in routing among excess rainfall components. This is particularly useful in analyzing the flood response of urbanized catchments where the distribution of excess rainfall into different vertical soil layers is quite different between the highly impervious urban areas (roads, rooftops, parking lots, etc.) and the more pervious suburban or rural areas of the basin (Smith et al., 2002; Mejía and Moglen, 2010; Mejía et al., 2015). We believe the time lag terms could be important for flood response of the urbanized catchment and our new framework can serve as a diagnostic tool to verify the significance of these terms.

We acknowledge certain limitations of our analytical framework study. The framework variables and flow simulation are dependent on the distributed hydrologic model devised in this study (vegetation interception, imperviousness areas, coefficient $\alpha$, etc.). Since the retrievals of framework variables are based on the model structure and parameterization, the way a variable is calculated could vary across models, while in certain models such an explicit parameter may not be available. An alternative path to circumventing this issue is to apply directly observed data for the calculation of the analytical framework variables. For instance, the vegetation interception can be estimated from the leaf area index data (Xiao et al., 2014), databases of the impervious area are provided in certain data-rich locations (Homer et al., 2015), and the spatial patterns of runoff coefficients could be retrieved in highly gauged catchments or from satellite-derived soil moisture fields at global scale (Merz and Blöschl, 2009; Penna et al., 2011; Dhakal et al., 2012; Massari et al., 2014). The parameters related to runoff routing could be estimated based on the geomorphologic properties of catchments (Shen et al., 2017).
Data availability. The $30 \mathrm{~s}$ resolution HydroSHEDS datasets used to build the catchments are available at https://hydrosheds.cr.usgs. gov/datadownload.php?reqdata=30demg (Lehner et al., 2008).

The stage 4 radar-based multi-sensor precipitation estimates may be obtained upon request from http://data.eol.ucar.edu/cgi-bin/ codiac/fgr_form/id=21.093 (Lin, 2011).

The North America Regional Reanalysis (NARR) product was obtained from ftp://nomads.ncdc.noaa.gov/NARR/ (Mesinger et al., 2006).

The USGS IDs of the three gauge stations are 02082950, 02083000, and 02082585. The instantaneous flow data of the three stations from before October 2007 were shared by Zachery Flamig at the University of Oklahoma via http://flash.ou.edu/ USGS/, and the records after October 2007 were downloaded via http://waterdata.usgs.gov/nwis, the USGS National Water Information System (NWISWeb).

The Coupled Routing and Excess STorage (CREST) distributed hydrological model version 2.1 (Matlab) was obtained from http: //hydro.ou.edu/research/crest/ (Shen et al., 2016; Shen and Hong, 2014).

The Matlab codes of CPM together with the user manual are available from http://ucwater.engr.uconn.edu/models-data/ (Mei and Anagnostou, 2015). 


\section{Appendix A: Catchment-average storm rainfall excess}

The catchment-average storm rainfall excess is calculated by integrating either $[R]_{\mathrm{a}}$ over the storm period or $[R]_{\mathrm{t}}$ over the catchment area. This means

$$
\begin{aligned}
& {[R]_{\mathrm{at}}=} \\
& \left\{\begin{array}{l}
\left.\frac{1}{\left|T_{\mathrm{P}}\right|} \int_{T_{\mathrm{P}}}[R]_{\mathrm{a}} \mathrm{d} t=[P]_{\mathrm{at}} \sum_{i=1}^{N}\left[W_{i}\right]_{\mathrm{at}}+\left\{[P]_{\mathrm{a}}, \sum_{i=1}^{N}\left[W_{i}\right]_{\mathrm{a}}\right\}+\left[\left\{P, \sum_{\mathrm{t}}^{N} W_{i}\right\}\right]_{\mathrm{a}}\right]_{\mathrm{t}} \\
\frac{1}{|A|} \int_{A}[R]_{\mathrm{t}} \mathrm{d} a=[P]_{\mathrm{at}} \sum_{i=1}^{N}\left[W_{i}\right]_{\mathrm{at}}+\left\{[P]_{\mathrm{t}}, \sum_{i=1}^{N}\left[W_{i}\right]_{\mathrm{t}}\right\}+\left[\left\{P, \sum_{\mathrm{a}}^{N} W_{i}\right\}\right]_{\mathrm{t}}
\end{array}\right.
\end{aligned}
$$

The last term of the second equation can be rewritten as

$$
\begin{aligned}
{\left[\left\{P, \sum_{i=1}^{N} W_{i}\right\}_{\mathrm{t}}\right]_{\mathrm{a}} } & =\frac{1}{|A|} \int_{A} \frac{1}{\left|T_{\mathrm{P}}\right|} \int_{T_{\mathrm{P}}}\left(P-[P]_{\mathrm{t}}\right)\left(\sum_{i=1}^{N} W_{i}\right. \\
& \left.-\sum_{i=1}^{N}\left[W_{i}\right]_{\mathrm{t}}\right) \mathrm{d} t \mathrm{~d} a,
\end{aligned}
$$

where

$P^{*}=P-[P]_{\mathrm{t}}$ and $W^{*}=\sum_{i=1}^{N} W_{i}-\sum_{i=1}^{N}\left[W_{i}\right]_{\mathrm{t}}$,

and the equation becomes

$$
\begin{aligned}
\frac{1}{|A|} \int_{A} \frac{1}{\left|T_{\mathrm{P}}\right|} \int_{T_{\mathrm{P}}} P^{*} W^{*} \mathrm{~d} t \mathrm{~d} a & =\frac{1}{\left|T_{\mathrm{P}}\right|} \int_{T_{\mathrm{P}}} \frac{1}{|A|} \int_{A} P^{*} W^{*} \mathrm{~d} a \mathrm{~d} t \\
& =\left[\left[P^{*} W^{*}\right]_{\mathrm{a}}\right]_{\mathrm{t}} .
\end{aligned}
$$

The second term of the first $[R]_{\text {at }}$ equation can be rewritten as

$$
\begin{aligned}
& \left\{[P]_{\mathrm{a}}, \sum_{i=1}^{N}\left[W_{i}\right]_{\mathrm{a}}\right\}_{\mathrm{t}}=\frac{1}{\left|T_{\mathrm{P}}\right|} \int_{T_{\mathrm{P}}}\left[\frac{1}{|A|} \int_{A}\left(P-[P]_{\mathrm{t}}\right) \mathrm{d} a\right] \\
& {\left[\frac{1}{|A|} \int_{A}\left(\sum_{i=1}^{N} W_{i}-\sum_{i=1}^{N}\left[W_{i}\right]_{\mathrm{t}}\right) \mathrm{d} a\right] \mathrm{d} t=\frac{1}{\left|T_{\mathrm{P}}\right|} \int_{T_{\mathrm{P}}}} \\
& \left(\frac{1}{|A|} \int_{A} P^{*} \mathrm{~d} t\right)\left(\frac{1}{|A|} \int_{A} W^{*} \mathrm{~d} t\right) \mathrm{d} a=\left[\left[P^{*}\right]_{\mathrm{a}}\left[W^{*}\right]_{\mathrm{a}}\right]_{\mathrm{t}} .
\end{aligned}
$$

Note that

$$
\begin{aligned}
{\left[\left[P^{*} W^{*}\right]_{\mathrm{a}}\right]_{\mathrm{t}}-\left[\left[P^{*}\right]_{\mathrm{a}}\left[W^{*}\right]_{\mathrm{a}}\right]_{\mathrm{t}} } & =\left[\left[P^{*} W^{*}\right]_{\mathrm{a}}-\left[P^{*}\right]_{\mathrm{a}}\left[W^{*}\right]_{\mathrm{a}}\right]_{\mathrm{t}} \\
& =\left[\left\{P^{*}, W^{*}\right\}_{\mathrm{a}}\right]_{\mathrm{t}} .
\end{aligned}
$$

Therefore,

$$
\left[\left\{P, \sum_{i=1}^{N} W_{i}\right\}_{\mathrm{a}}\right]_{\mathrm{t}}-\left\{[P]_{\mathrm{t}}, \sum_{i=1}^{N}\left[W_{i}\right]_{\mathrm{t}}\right\}_{\mathrm{a}}
$$

$$
=\left[\left\{\left(P-[P]_{\mathrm{t}}\right), \sum_{i=1}^{N}\left(W_{i}-\left[W_{i}\right]_{\mathrm{t}}\right)\right\}_{\mathrm{a}}\right]_{\mathrm{t}} .
$$

By replacing $\left[\left\{P, \sum_{i=1}^{N} W_{i}\right\}_{\mathrm{a}}\right]_{\mathrm{t}}$ in the first equation of $[R]_{\mathrm{at}}$, Eq. (9) is attained.

\section{Appendix B: Expectation of rainfall excess generation time}

The rainfall excess generation time is modeled by the instantaneous time, $T . T$ is a variable in time and follows a uniform distribution over the event period $T_{\mathrm{P}}$. Therefore,

$$
\begin{aligned}
E_{i}\left(T_{\mathrm{r}, i}\right) & =\frac{1}{\left|T_{\mathrm{P}}\right|} \int_{T_{\mathrm{P}}} \frac{1}{|A|} \int_{A} \frac{T \cdot R_{i}}{\left[R_{i}\right]_{\mathrm{at}}} \mathrm{d} a \mathrm{~d} t=\frac{1}{\left|T_{\mathrm{P}}\right|} \int_{T_{\mathrm{P}}} \frac{T \cdot\left[R_{i}\right]_{\mathrm{a}}}{\left[R_{i}\right]_{\mathrm{at}}} \mathrm{d} t \\
& =[T]_{\mathrm{t}}+\frac{\left\{T,\left[R_{i}\right]_{\mathrm{a}}\right\}_{\mathrm{t}}}{\left[R_{i}\right]_{\mathrm{at}}} .
\end{aligned}
$$

Since $T$ follows a uniform distribution on $T_{\mathrm{P}}$, the solution of $[T]_{\mathrm{t}}$ is

$$
[T]_{\mathrm{t}}=\int_{T_{\mathrm{P}}} \frac{T}{\left|T_{\mathrm{P}}\right|} \mathrm{d} T=\frac{\left|T_{\mathrm{P}}\right|}{2} .
$$

For the case of total rainfall excess generation time, write

$$
\begin{aligned}
E\left(T_{\mathrm{r}}\right) & =\frac{1}{\mid T_{\mathrm{P} \mid}} \int_{T_{\mathrm{P}}} \frac{1}{|A|} \int_{A}\left(T \cdot \sum_{i}^{N} \psi_{i} \frac{R_{i}}{\left[R_{i}\right]_{\mathrm{at}}}\right) \mathrm{d} a \mathrm{~d} t \\
& =\sum_{i}^{N} \psi_{i} \frac{1}{\left|T_{\mathrm{P}}\right|} \int_{T_{\mathrm{P}}} \frac{1}{|A|} \int_{A} \frac{T \cdot R_{i}}{\left[R_{i}\right]_{\mathrm{at}}} \mathrm{d} a \mathrm{~d} t=\sum_{i}^{N} \psi_{i} E_{i}\left(T_{\mathrm{r}, i}\right) .
\end{aligned}
$$

\section{Appendix C: Expectation of runoff routing time}

The runoff routing time is modeled by a spatial variable routing time, $\Theta_{i}$; write

$$
\begin{aligned}
E_{i}\left(T_{\mathrm{n}, i}\right) & =\frac{1}{\left|T_{\mathrm{P}}\right|} \int_{T_{\mathrm{P}}} \frac{1}{|A|} \int_{A} \frac{\Theta_{i} R_{i}}{\left[R_{i}\right]_{\mathrm{at}}} \mathrm{d} a \mathrm{~d} t=\frac{1}{|A|} \int_{A} \frac{\Theta_{i}\left[R_{i}\right]_{t}}{\left[R_{i}\right]_{\mathrm{at}}} \mathrm{d} a \\
& =\left[\Theta_{i}\right]_{\mathrm{a}}+\frac{\left\{\Theta_{i},\left[R_{i}\right]_{\mathrm{t}}\right\}_{\mathrm{a}}}{\left[R_{i}\right]_{\mathrm{at}}} .
\end{aligned}
$$

The channel routing time for the total flow is modeled by $\Theta$ which is a function of $\Theta_{i}$ (Eq. 20). Write

$$
\begin{aligned}
E\left(T_{\mathrm{n}}\right) & =\frac{1}{\left|T_{\mathrm{P}}\right|} \int_{T_{\mathrm{P}}} \frac{1}{|A|} \int_{A}\left(\Theta \cdot \sum_{i}^{N} \psi_{i} \frac{R_{i}}{\left[R_{i}\right]_{\mathrm{at}}}\right) \mathrm{d} a \mathrm{~d} t \\
& =\frac{1}{\left|T_{\mathrm{P}}\right|} \int_{T_{\mathrm{P}}} \frac{1}{|A|} \int_{A}\left(\sum_{i}^{N} \xi_{i} \Theta_{i} \psi_{i} \frac{R_{i}}{\left[R_{i}\right]_{\mathrm{at}}}\right) \mathrm{d} a \mathrm{~d} t
\end{aligned}
$$




$$
\begin{aligned}
& =\sum_{i}^{N} \psi_{i} \xi_{i} \frac{1}{\left|T_{\mathrm{P}}\right|} \int_{T_{\mathrm{P}}} \frac{1}{|A|} \int_{A} \frac{\Theta_{i} R_{i}}{\left[R_{i}\right]_{\mathrm{at}}} \mathrm{d} a \mathrm{~d} t \\
& =\sum_{i}^{N} \psi_{i} \xi_{i} E_{i}\left(T_{\mathrm{h}, i}\right) .
\end{aligned}
$$

\section{Appendix D: Variance of rainfall excess generation time}

For the variance of rainfall excess generation time, we first define $E_{i}\left(T_{\mathrm{r}, i}^{2}\right)$ as

$$
E_{i}\left(T_{\mathrm{r}, i}^{2}\right)=\frac{1}{\left|T_{\mathrm{P}}\right|} \int_{T_{\mathrm{P}}} \frac{1}{|A|} \int_{A} \frac{T^{2} R_{i}}{\left[R_{i}\right]_{\mathrm{at}}} \mathrm{d} a \mathrm{~d} t=\left[T^{2}\right]_{\mathrm{t}}+\frac{\left\{T^{2},\left[R_{i}\right]_{\mathrm{a}}\right\}_{\mathrm{t}}}{\left[R_{i}\right]_{\mathrm{at}}} .
$$

The variance of rainfall excess generation time for component $i$ is then calculated as

$$
\begin{aligned}
\operatorname{var}_{i}(T) & =E_{i}\left(T^{2}\right)-\left[E_{i}(T)\right]^{2}=\left\{T^{2}\right\}_{\mathrm{t}} \\
& +\frac{\left\{T^{2},\left[R_{i}\right]_{\mathrm{a}}\right\}_{\mathrm{t}}-\left|T_{\mathrm{P}}\right|\left\{T,\left[R_{i}\right]_{\mathrm{a}}\right\}_{\mathrm{t}}}{\left[R_{i}\right]_{\mathrm{at}}}-\left(\frac{\left\{T,\left[R_{i}\right]_{\mathrm{a}}\right\}_{\mathrm{t}}}{\left[R_{i}\right]_{\mathrm{at}}}\right)^{2} \\
& =\frac{\left|T_{\mathrm{P}}\right|^{2}}{12}+\frac{\left\{T^{2},\left[R_{i}\right]_{\mathrm{a}}\right\}_{\mathrm{t}}-\left|T_{\mathrm{P}}\right|\left\{T,\left[R_{i}\right]_{\mathrm{a}}\right\}_{\mathrm{t}}}{\left[R_{i}\right]_{\mathrm{at}}} \\
& -\left(\frac{\left\{T,\left[R_{i}\right]_{\mathrm{a}}\right\}_{\mathrm{t}}}{\left[R_{i}\right]_{\mathrm{at}}}\right)^{2} .
\end{aligned}
$$

The solution for $\left\{T^{2}\right\}_{\mathrm{t}}$ is provided as

$$
\left\{T^{2}\right\}_{\mathrm{t}}=\left[T^{2}\right]_{\mathrm{t}}-[T]_{\mathrm{t}}^{2}=\frac{\left|T_{\mathrm{P}}\right|^{2}}{3}
$$

For the case of $\operatorname{var}\left(T_{\mathrm{r}}\right)$, it is trivial to show

$$
E\left(T_{\mathrm{r}}^{2}\right)=\sum_{i}^{N} \psi_{i} E_{i}\left(T_{\mathrm{r}, i}^{2}\right)
$$

Thus,

$$
\begin{aligned}
\operatorname{var}\left(T_{\mathrm{r}}\right) & =E\left(T_{\mathrm{r}}^{2}\right)-\left[E\left(T_{\mathrm{r}}\right)\right]^{2}=\sum_{i}^{N} \psi_{i} E_{i}\left(T_{\mathrm{r}, i}^{2}\right)-\left[E\left(T_{\mathrm{r}}\right)\right]^{2} \\
& =\sum_{i}^{N} \psi_{i} E_{i}\left(T_{\mathrm{r}, i}^{2}\right)-\sum_{i}^{N} \psi_{i}\left[E_{i}\left(T_{\mathrm{r}, i}\right)\right]^{2} \\
& +\sum_{i}^{N} \psi_{i}\left[E_{i}\left(T_{\mathrm{r}, i}\right)\right]^{2}-2\left[E\left(T_{\mathrm{r}}\right)\right]^{2}+\left[E\left(T_{\mathrm{r}}\right)\right]^{2} \\
& =\sum_{i}^{N} \psi_{i}\left\{E_{i}\left(T_{\mathrm{r}, i}^{2}\right)-\left[E_{i}\left(T_{\mathrm{r}, i}\right)\right]^{2}\right\} \\
& +\sum_{i}^{N} \psi_{i}\left\{\left[E_{i}\left(T_{\mathrm{r}, i}\right)\right]^{2}-2 E_{i}\left(T_{\mathrm{r}, i}\right) E\left(T_{\mathrm{r}}\right)+\left[E\left(T_{\mathrm{r}}\right)\right]^{2}\right\} \\
& =\sum_{i}^{N} \psi_{i} \operatorname{var}_{i}\left(T_{\mathrm{r}, i}\right)+\sum_{i}^{N} \psi_{i}\left[E_{i}\left(T_{\mathrm{r}, i}\right)-E\left(T_{\mathrm{r}}\right)\right]^{2}
\end{aligned}
$$

\section{Appendix E: Variance of runoff routing time}

Similarly, for the variance of runoff routing time, as the first step, we find $E_{i}\left(T_{\mathrm{n}, i}^{2}\right)$ as

$$
E_{i}\left(T_{\mathrm{n}, i}^{2}\right)=\frac{1}{\left|T_{\mathrm{P}}\right|} \int_{T_{\mathrm{P}}} \frac{1}{|A|} \int_{A} \frac{\Theta_{i}^{2} R_{i}}{\left[R_{i}\right]_{\mathrm{at}}} \mathrm{d} a \mathrm{~d} t=\left[\Theta_{i}^{2}\right]_{\mathrm{a}}+\frac{\left\{\Theta_{i}^{2},\left[R_{i}\right]_{\mathrm{t}}\right\}_{\mathrm{a}}}{\left[R_{i}\right]_{\mathrm{at}}} .
$$

The variance of runoff routing time for one component is then calculated as

$$
\begin{aligned}
\operatorname{var}_{i}\left(T_{\mathrm{n}, i}\right) & =E_{i}\left(T_{\mathrm{n}, i}^{2}\right)-\left[E_{i}\left(T_{\mathrm{n}, i}\right)\right]^{2} \\
& =\left\{\Theta_{i}\right\}_{\mathrm{a}}+\frac{\left\{\Theta_{i}^{2},\left[R_{i}\right]_{\mathrm{t}}\right\}_{\mathrm{a}}-2\left[\Theta_{i}\right]_{\mathrm{a}}\left\{\Theta_{i},\left[R_{i}\right]_{\mathrm{t}}\right\}_{\mathrm{a}}}{\left[R_{i}\right]_{\mathrm{at}}} \\
& -\left(\frac{\left\{\Theta_{i},\left[R_{i}\right]_{\mathrm{t}}\right\}_{\mathrm{a}}}{\left[R_{i}\right]_{\mathrm{at}}}\right)^{2} .
\end{aligned}
$$

For the $\operatorname{var}\left(T_{\mathrm{n}}\right)$, we know the following:

$$
E\left(T_{\mathrm{n}}^{2}\right)=\sum_{i}^{N} \psi_{i} \xi_{i}^{2} E_{i}\left(T_{\mathrm{n}, i}^{2}\right)
$$

Using the property of variance, write

$$
\begin{aligned}
\operatorname{var}\left(T_{\mathrm{n}}\right) & =E\left(T_{\mathrm{n}}^{2}\right)-\left[E\left(T_{\mathrm{n}}\right)\right]^{2}=\sum_{i}^{N} \psi_{i} \xi_{i}^{2} E_{i}\left(T_{\mathrm{n}, i}^{2}\right) \\
& -\left[E\left(T_{\mathrm{n}}\right)\right]^{2}=\sum_{i}^{N} \psi_{i} \xi_{i}^{2} E_{i}\left(T_{\mathrm{n}, i}^{2}\right) \\
& -\sum_{i}^{N} \psi_{i} \xi_{i}^{2}\left[E_{i}\left(T_{\mathrm{n}, i}\right)\right]^{2}+\sum_{i}^{N} \psi_{i} \xi_{i}^{2}\left[E_{i}\left(T_{\mathrm{n}, i}\right)\right]^{2} \\
& -2\left[E\left(T_{\mathrm{n}}\right)\right]^{2}+\left[E\left(T_{\mathrm{n}}\right)\right]^{2}=\sum_{i}^{N} \psi_{i} \xi_{i}^{2}\left\{E_{i}\left(T_{\mathrm{n}, i}^{2}\right)\right. \\
& \left.-\left[E_{i}\left(T_{\mathrm{n}, i}\right)\right]^{2}\right\}+\sum_{i}^{N} \psi_{i}\left\{\left[\xi_{i} E_{i}\left(T_{\mathrm{n}, i}\right)\right]^{2}\right. \\
& \left.-2 \xi_{i} E_{i}\left(T_{\mathrm{n}, i}\right)\left[E\left(T_{\mathrm{n}}\right)\right]+\left[E\left(T_{\mathrm{n}}\right)\right]^{2}\right\} \\
& =\sum_{i}^{N} \psi_{i} \xi_{i}^{2} \operatorname{var}_{i}\left(T_{\mathrm{n}, i}\right)+\sum_{i}^{N} \psi_{i}\left[\xi_{i} E_{i}\left(T_{\mathrm{n}, i}\right)\right. \\
& \left.-E\left(T_{\mathrm{n}}\right)\right]^{2} .
\end{aligned}
$$

\section{Appendix F: Covariance between rainfall excess generation and runoff routing time}

The covariance between holding times of the two stages is calculated by finding $E_{i}\left(T_{\mathrm{r}, i} T_{\mathrm{n}, i}\right)$ :

$E_{i}\left(T_{\mathrm{r}, i} T_{\mathrm{n}, i}\right)=\frac{1}{\left|T_{\mathrm{P}}\right|} \int_{T_{\mathrm{P}}} \frac{1}{|A|} \int_{A}\left(\frac{T \cdot \Theta_{i} \cdot R_{i}}{\left[R_{i}\right]_{\mathrm{at}}}\right) \mathrm{d} a \mathrm{~d} t$ 


$$
\begin{aligned}
& =[T]_{\mathrm{t}}\left[\Theta_{i}\right]_{\mathrm{a}}+\frac{\left[\Theta_{i}\right]_{\mathrm{a}}\left\{T,\left[R_{i}\right]_{\mathrm{a}}\right\}_{\mathrm{t}}}{\left[R_{i}\right]_{\mathrm{at}}} \\
& +\frac{[T]_{\mathrm{t}}\left\{\Theta_{i},\left[R_{i}\right]_{\mathrm{t}}\right\}_{\mathrm{a}}}{\left[R_{i}\right]_{\mathrm{at}}}+\frac{\left\{T,\left\{\Theta_{i}, R_{i}\right\}_{\mathrm{a}}\right\}_{\mathrm{t}}}{\left[R_{i}\right]_{\mathrm{at}}} .
\end{aligned}
$$

Then, the covariance is defined as

$$
\begin{aligned}
\operatorname{cov}_{i}\left(T_{\mathrm{r}, i}, T_{\mathrm{n}, i}\right) & =E_{i}\left(T_{\mathrm{r}, i} T_{\mathrm{n}, i}\right)-E_{i}\left(T_{\mathrm{r}, i}\right) E_{i}\left(T_{\mathrm{n}, i}\right) \\
& =\frac{\left\{T,\left\{\Theta_{i}, R_{i}\right\}_{\mathrm{a}}\right\}_{\mathrm{t}}}{\left[R_{i}\right]_{\mathrm{at}}}-\frac{\left\{T,\left[R_{i}\right]_{\mathrm{a}}\right\}_{\mathrm{t}}\left\{\Theta_{i},\left[R_{i}\right]_{\mathrm{t}}\right\}_{\mathrm{a}}}{\left[R_{i}\right]_{\mathrm{at}}^{2}} .
\end{aligned}
$$

For the $\operatorname{cov}\left(T_{\mathrm{r}}, T_{\mathrm{n}}\right)$, it is trivial to show

$E\left(T_{\mathrm{r}} T_{\mathrm{n}}\right)=\sum_{i}^{N} \psi_{i} \xi_{i} E_{i}\left(T_{\mathrm{r}, i} T_{\mathrm{n}, i}\right)$.
Write

$$
\begin{aligned}
\operatorname{cov}\left(T_{\mathrm{r}}, T_{\mathrm{n}}\right) & =E\left(T_{\mathrm{r}} T_{\mathrm{n}}\right)-E\left(T_{\mathrm{r}}\right) E\left(T_{\mathrm{n}}\right) \\
& =\sum_{i}^{N} \psi_{i} \xi_{i} E_{i}\left(T_{\mathrm{r}, i} T_{\mathrm{n}, i}\right)-E\left(T_{\mathrm{r}}\right) E\left(T_{\mathrm{n}}\right) \\
& =\sum_{i}^{N} \psi_{i} \xi_{i} E_{i}\left(T_{\mathrm{r}, i} T_{\mathrm{n}, i}\right)-\sum_{i}^{N} \psi_{i} E_{i}\left(T_{\mathrm{r}, i}\right) \xi_{i} E_{i}\left(T_{\mathrm{n}, i}\right) \\
& +\sum_{i}^{N} \psi_{i} E_{i}\left(T_{\mathrm{r}, i}\right) \xi_{i} E_{i}\left(T_{\mathrm{n}, i}\right)-E\left(T_{\mathrm{r}}\right) E\left(T_{\mathrm{n}}\right) \\
& =\sum_{i}^{N} \psi_{i} \xi_{i} \operatorname{cov}_{i}\left(T_{\mathrm{r}, i}, T_{\mathrm{n}, i}\right) \\
& +\sum_{i}^{N} \psi_{i}\left[E_{i}\left(T_{\mathrm{r}, i}\right) \xi_{i} E_{i}\left(T_{\mathrm{n}, i}\right)-E\left(T_{\mathrm{r}}\right) E\left(T_{\mathrm{n}}\right)\right] .
\end{aligned}
$$




\section{The Supplement related to this article is available online at doi:10.5194/hess-21-2277-2017-supplement.}

Competing interests. The authors declare that they have no conflict of interest.

Acknowledgements. The current study was supported by a research grant from the Connecticut Institute for Resilience and Climate Adaptation.

Edited by: T. Kjeldsen

Reviewed by: two anonymous referees

\section{References}

Blöschl, G.: On the Fundamentals of Hydrological Sciences, in: Encyclopedia of Hydrological Sciences, John Wiley \& Sons, Ltd, Chichester, 2006.

Blöschl, G., Reszler, C., and Komma, J.: A spatially distributed flash flood forecasting model, Environ. Model. Softw., 23, 464-478, doi:10.1016/j.envsoft.2007.06.010, 2008.

Dhakal, N., Fang, X., Cleveland, T. G., Thompson, D. B., Asquith, W. H., and Marzen, L. J.: Estimation of Volumetric Runoff Coefficients for Texas Watersheds Using Land-Use and Rainfall-Runoff Data, J. Irrig. Drain Eng., 138, 43-54, doi:10.1061/(ASCE)IR.1943-4774.0000368, 2012.

Duan, Q., Sorooshian, S., and Gupta, V.: Effective and efficient global optimization for conceptual rainfall-runoff models, Water Resour. Res., 28, 1015-1031, doi:10.1029/91WR02985, 1992.

Gonzales, A. L., Nonner, J., Heijkers, J., and Uhlenbrook, S.: Comparison of different base flow separation methods in a lowland catchment, Hydrol. Earth Syst. Sci., 13, 2055-2068, doi:10.5194/hess-13-2055-2009, 2009.

Homer, C., Dewitz, J., Yang, L., Jin, S., Danielson, P., Xian, G., Coulston, J., Herold, N., Wickham, J., and Megown, K.: Completion of the 2011 National Land Cover Database for the Conterminous United States - Representing a Decade of Land Cover Change Information, Photogramm. Eng. Rem. S., 81, 345-354, 2015.

Koren, V., Reed, M., Zhang, Z., and Seo, D.-J.: Hydrology laboratory research modeling system (HL-RMS) of the US national weather service, J. Hydrol., 291, 297-318, doi:10.1016/j.jhydrol.2003.12.039, 2004.

Lehner, B., Verdin, K., and Jarvis, A.: New global hydrography derived from spaceborne elevation data, Eos Trans. AGU, 89, 9394, 2008.

Lin, Y.: GCIP/EOP Surface: Precipitation NCEP/EMC 4KM Gridded Data (GRIB) Stage IV Data, Version 1.0, UCAR/NCAR Earth Observing Laboratory, http://data.eol.ucar.edu/dataset/21. 093 (last access: 1 April 2017), 2011.

Lin, Y. and Mitchell, K. E.: The NCEP stage II/IV hourly precipitation analyses: Development and applications, in: 19th Conf. Hydrology, American Meteorological Society, 10 January 2005, San Diego, CA, USA, 2005.

Liu, F., Williams, M. W., and Caine, N.: Source waters and flow paths in an alpine catchment, Colorado Front
Range, United States, Water Resour. Res., 40, W09401, doi:10.1029/2004WR003076, 2004.

Massari, C., Brocca, L., Barbetta, S., Papathanasiou, C., Mimikou, M., and Moramarco, T.: Using globally available soil moisture indicators for flood modelling in Mediterranean catchments, Hydrol. Earth Syst. Sci., 18, 839-853, doi:10.5194/hess-18-8392014, 2014.

Mei, Y. and Anagnostou, E. N.: A Hydrograph Separation Method Based on Information from Rainfall and Runoff Records, J. Hydrol., 523, 636-649, doi:10.1016/j.jhydrol.2015.01.083, 2015.

Mei, Y., Anagnostou, E. N., Stampoulis, D., Nikolopoulos, E. I., Borga, M., and Vegara, H. J.: Rainfall Organization Control on the Flood Response of Mild-slope Basins, J. Hydrol., 510, 565577, doi:10.1016/j.jhydrol.2013.12.013, 2014.

Mejía, A. I. and Moglen, G. E.: Spatial distribution of imperviousness and the space-time variability of rainfall, runoff generation, and routing, Water Resour. Res., 46, W07509, doi:10.1029/2009WR008568, 2010.

Mejía, A. I., Rossel, F., Gironás, J., and Jovanovic, T.: Anthropogenic controls from urban growth on flow regimes, Adv. Water Resour., 84, 125-135, doi:10.1016/j.advwatres.2015.08.010, 2015.

Merz, R. and Blöschl, G.: A regional analysis of event runoff coefficients with respect to climate and catchment characteristics in Austria, Water Resour. Res., 45, W01405, doi:10.1029/2008WR007163, 2009.

Mesinger, F., DiMego, G., Kalnay, E., Mitchell, K., Shafran, P. C., Ebisuzaki, W., Jović, D., Woollen, J., Rogers, E., Berbery, E. H., Ek, M. B., Fan, Y., Grumbine, R., Higgins, W., Li, H., Lin, Y., Manikin, G., Parrish, D., and Shi, W.: North American Regional Reanalysis, B. Am. Meteorol. Soc., 87, 343-360, doi:10.1175/BAMS-87-3-343, 2006.

Moriasi, D. N., Arnold, J. G., Van Liew, M. W., Bingner, R. L., Harmel, R. D., and Veith, T. L.: Model Evaluation Guidelines for Systematic Quantification of Accuracy in Watershed Simulations, T. ASABE, 50, 885-900, doi:10.13031/2013.23153, 2007.

Nikolopoulos, E., Borga, M., Zoccatelli, D., and Anagnostou, E.: Catchment scale storm velocity: Quantification, scale dependence and effect on flood response, Hydrolog. Sci. J., 59, 13631379, doi:10.1080/02626667.2014.923889, 2014.

Palleiro, L., Rodríguez-Blanco, M. L., Taboada-Castro, M. M., and Taboada-Castro, M. T.: Hydrological response of a humid agroforestry catchment at different time scales, Hydrol. Process., 28, 1677-1688, doi:10.1002/hyp.9714, 2014.

Penna, D., Tromp-van Meerveld, H. J., Gobbi, A., Borga, M., and Dalla Fontana, G.: The influence of soil moisture on threshold runoff generation processes in an alpine headwater catchment, Hydrol. Earth Syst. Sci., 15, 689-702, doi:10.5194/hess-15-6892011, 2011.

Rodríguez-Blanco, M. L., Taboada-Castro, M. M., and TaboadaCastro, M. T.: Rainfall-runoff response and event-based runoff coefficients in a humid area (northwest Spain), Hydrolog. Sci. J., 57, 445-459, doi:10.1080/02626667.2012.666351, 2012.

Rodríguez-Iturbe, I. and Valdés, J. B.: The geomorphologic structure of hydrologic response, Water Resour. Res., 15, 1409-1420, doi:10.1029/WR015i006p01409, 1979.

Sangati, M., Borga, M., Rabuffetti, D., and Bechini, R.: Influence of rainfall and soil properties spatial aggregation on extreme flash flood response modelling: An evaluation based on the Sesia river 
basin, North Western Italy, Adv. Water Resour., 32, 1090-1106, doi:10.1016/j.advwatres.2008.12.007, 2009.

Shen, X. and Hong, Y.: CREST - The Coupled Routing and Excess STorage user manual version 2.1, User Manual, Hydrometeorology and Remote Sensing Laboratory, National Weather Center, Norman, OK, USA, 1-25, 2014.

Shen, X., Hong, Y., Zhang, K., and Hao, Z.: Refine a Distributed Linear Reservoir Routing Method to Improve Performance of the CREST Model, J. Hydrol. Eng., 22, 04016061, doi:10.1061/(ASCE)HE.1943-5584.0001442, 2016.

Shen, X., Anagnostou, E. N., Mei, Y., and Hong, Y.: A global distributed basin morphometric dataset, Sci. Data., 4, 160124, doi:10.1038/sdata.2016.124, 2017.

Sivapalan, M., Blöschl, G., Merz, R., and Gutknecht, D.: Linking flood frequency to long-term water balance: Incorporating effects of seasonality, Water Resour. Res., 41, W06012, doi:10.1029/2004WR003439, 2004.

Skøien, J. O. and Blöschl, G.: Catchments as space-time filters - a joint spatio-temporal geostatistical analysis of runoff and precipitation, Hydrol. Earth Syst. Sci., 10, 645-622, doi:10.5194/hess10-645-2006, 2006.

Skøien, J. O., Blöschl, G., and Western, A. W.: Characteristic space scales and timescales in hydrology, Water Resour. Res., 39, 1304, doi:10.1029/2002WR001736, 2003.

Smith, J. A., Baeck, M. L., Morrison, J. E., Turner-Gillespie, D. F., and Bates, P. D.: The Regional Hydrology of Extreme Floods in an Urbanizing Drainage Basin, J. Hydrometeorol., 3, 267-282, doi:10.1175/1525-7541(2002)003<0267:TRHOEF>2.0.CO;2, 2002.

Smith, J. A., Baeck, M. L., Meierdiercks, K. L., Nelson, P. A., Miller, A. J., and Holland, E. J.: Field studies of the storm event hydrologic response in an urbanizing watershed, Water Resour. Res., 41, W10413, doi:10.1029/2004WR003712, 2005.

Smith, M. B., Koren, V. I., Zhang, Z., Reed, S. M., Pan, J.-J., and Moreda, F.: Runoff response to spatial variability in precipitation: an analysis of observed data, J. Hydrol., 298, 267-286, doi:10.1016/j.jhydrol.2004.03.039, 2004.

Viglione, A., Chirico, G. B., Woods, R., and Blöschl, G.: Generalised synthesis of space-time variability in flood response: An analytical framework, J. Hydrol., 394, 198-212, doi:10.1016/j.jhydrol.2010.05.047, 2010a.
Viglione, A., Chirico, G. B., Komma, J., Woods, R., Borga, M., and Blöschl, G.: Quantifying space-time dynamics of flood event types, J. Hydrol., 394, 213-229, doi:10.1016/j.jhydrol.2010.05.041, 2010b.

Volpi, E., Di Lazzaro, M., and Fiori, A.: A simplified framework for assessing the impact of rainfall spatial variability on the hydrologic response, Adv. Water Resour., 46, 1-10, doi:10.1016/j.advwatres.2012.04.011, 2012.

Wang, J., Hong, Y., Li, L., Gourley, J. J., Khan, S. I., Yilmaz, K. K., Adler, R. F. Policelli, F. S. Habib, S., Irwn, D., Limaye, A. S., Korme, T., and Okello, L.: The coupled routing and excess storage (CREST) distributed hydrological model, Hydrolog. Sci. J., 56, 84-98, doi:10.1080/02626667.2010.543087, 2011.

Weiler, M., McGlynn, B. L., McGuire, K. J., and McDonnell, J. J.: How does rainfall become runoff? A combined tracer and runoff transfer function approach, Water Resour. Res., 39, 1315, doi:10.1029/2003WR002331, 2003.

Woods, R. A. and Sivapalan, M.: A synthesis of spacetime variability in storm response: Rainfall, runoff generation, and routing, Water Resour. Res., 35, 2469-2485, doi:10.1029/1999WR900014, 1999.

Xiao, Z., Liang, S., Wang J., Chen, P., Yin, X., Zhang, L., and Song, J.: Use of general regression neural networks for generating the GLASS leaf area index product from time-series MODIS surface reflectance, IEEE T. Geosci. Remote, 52, 209223, doi:10.1109/TGRS.2013.2237780, 2014.

Zhao, R.-J.: The Xinanjiang model applied in China, J. Hydrol., 135, 371-381, doi:10.1016/0022-1694(92)90096-E, 1992.

Zoccatelli, D., Borga, M., Zannon, F., Antonescu, B., and Stancalie, G.: Which rainfall spatial information for flash flood response modelling? A numerical investigation based on data from the Carpathian range, Romania, J. Hydrol., 394, 148-161, doi:10.1016/j.jhydrol.2010.07.019, 2010.

Zoccatelli, D., Borga, M., Viglione, A., Chirico, G. B., and Blöschl, G.: Spatial moments of catchment rainfall: rainfall spatial organisation, basin morphology, and flood response, Hydrol. Earth Syst. Sci., 15, 3767-3783, doi:10.5194/hess-15-37672011, 2011.

Zoccatelli, D., Borga, M., Chirico, G., and Nikolopoulos, E. I.: The relative role of hillslope and river network routing in the hydrologic response to spatially variable rainfall fields, J. Hydrol., 531, 349-359, doi:10.1016/j.jhydrol.2015.08.014, 2015. 